\title{
Experimental and Numerical Simulation to Validate Critical Perforation Velocity on a Flat Plate Aluminium Alloy 6061
}

\author{
Bharosh Kumar Yadav $\mathbb{D}^{1,2}$ Mehdi Jahangiri $\mathbb{D}^{3},{ }^{3}$ and Dalbir Singh $\mathbb{D}^{4}$ \\ ${ }^{1}$ School of Aeronautics, Department of Aeronautical Structural Engineering, \\ Faculty Solid Mechanics,Northwestern Polytechnical University, Xi'an 710072, Shaanxi Province, China \\ ${ }^{2}$ Department of Mechanical Engineering, Institute of Engineering (IOE), Tribhuvan University (TU),Purwanchal Campus, \\ Dharan-08, Nepal \\ ${ }^{3}$ Department of Mechanical Engineering, Shahrekord Branch, Islamic Azad University, Shahrekord, Iran \\ ${ }^{4}$ Department of Aeronautical Engineering, Hindustan Institute of Technology and Science (Deemed to Be University), Chennai, \\ Tamilnadu, India \\ Correspondence should be addressed to Bharosh Kumar Yadav; bharosh@ioepc.edu.np
}

Received 11 November 2021; Revised 16 January 2022; Accepted 24 January 2022; Published 24 February 2022

Academic Editor: Bingxiang Yuan

Copyright (C) 2022 Bharosh Kumar Yadav et al. This is an open access article distributed under the Creative Commons Attribution License, which permits unrestricted use, distribution, and reproduction in any medium, provided the original work is properly cited.

\begin{abstract}
Aluminium 6061 (Al6061) alloy, which is known as commercial alloy, is massively used in aviation and automobile industries. Therefore, research on Al6061 alloy is gaining significance among scientists and researchers all over the world as it provides light weight, high strength and stiffness, high impact, and corrosion resistance in engineering applications. The comprehensive analysis of mechanical behavior under large stress-strain deformation responses of the alloy is studied over a wide range of strain-rates such as $1 \times 10^{-3} \mathrm{~s}^{-1}, 1 \times 10^{3} \mathrm{~s}^{-1}, 2 \times 10^{3} \mathrm{~s}^{-1}$, and $3 \times 10^{3} \mathrm{~s}^{-1}$ under room temperature to elevated temperatures of $100^{\circ} \mathrm{C}$ and $200^{\circ} \mathrm{C}$. In this regard, this study aims to evaluate the Johnson-Cook strength and fracture constants utilizing the Johnson-Cook constitutive model equations. Furthermore, the evaluated constant parameters have been used to perform numerical simulation analysis utilizing ABAQUS/CAE software. According to the study's findings, the critical perforation velocity was found to be $70 \mathrm{~ms}^{-1}$ when a flat-nosed bullet $(45 \mathrm{~mm}$ length and $12 \mathrm{~mm}$ diameter) made of stainless steel weighing 50 grams was fired normally to the center of a square plate specimen of Al6061 alloy. The specimen of the square flat plate was prepared with side $205 \mathrm{~mm}$ and $2 \mathrm{~mm}$ thickness $\left(205 \times 205 \times 2 \mathrm{~mm}^{3}\right)$. A good correlation for critical perforation velocity of experimental acquisition data and numerical simulation results has been found. These findings increase the knowledge of the material's response application to the high-velocity impact that can be used in arms-ammunition, aviation, marine, automobile, and home appliances.
\end{abstract}

\section{Introduction}

1.1. Background. Aluminium 6061 alloy is one of the commercial aluminum alloys being massively used in aerospace and automobile industries; it is a versatile heat treatable extruded alloy with medium to high strength capabilities. The typical application for aluminium alloy includes Aircraft and Aerospace components, Marine fittings, Transport, Bicycle frames, Vehicle rims, Camera lenses, Driveshaft, Electrical fittings and connectors, Brake components, Valves, Couplings, etc. [1,2]. Researchers are working to develop materials that have light weight, high strength and stiffness, high impact, and corrosion resistance as they are widely used in structural application. Al6061 alloy is used as structural components in the aerospace, aeronautical, marine, and automobile industries. Al6061-T6 increases high toughness and weldability and found more application potential [3-5].

1.2. Literature Review. A few recent studies reported on the mechanical strength and fracture behavior application to high-velocity bullet impact on aluminum 6061 alloys. Some of the relevant research is discussed in the following section. 
Due to rapid simultaneous advancement in hardware technologies as well as in mechanics and material modeling during the last decades, engineers are nowadays able to analyze complex structures undergoing static and dynamic loading conditions in many engineering disciplines. In addition, high strain-rate deformations such as dynamic and high-velocity impact have increasing importance in industrial applications. Complex thermo-mechanical processes and numerical solution procedures such as the finite element method for solving strongly coupled mechanical and thermal boundary-value problems practices are gaining significantly in engineering fields [6-13]. Rathore et al. studied numerical simulation for Aluminium alloy 6060 to predict fracture behavior under the highvelocity impact of the flat-faced rigid circular projectile and the comparative effect has been studied in the range of $100 \mathrm{~m} / \mathrm{s}, 150 \mathrm{~m} / \mathrm{s}$, and $250 \mathrm{~m} / \mathrm{s}$. They found plugging behavior and material experience shear-type deformation projectile impacting at high velocity [14]. Rai et al. performed ballistic impact on aluminium 5083-H116 plate numerically with Johnson Cook plastic model and their study was verified by hand calculations and engineering judgment. They conclude the Johnson Cook failure model was not able to capture scabbing phenomena, eventually ballistic resistance was overestimated in numerical simulation [15]. Senthil and Iqbal predict superior layer of armour steel, mild steel, and aluminum 7075-T651 alloy against 7.62 AP projectile, and the behavior was predicted by incorporating the Johnson Cook model [16]. Borvik et al. studied experimentally and numerically normal and oblique impact of $20 \mathrm{~mm}$ thick AA6082-T4 aluminium plates and the material parameters were identified utilizing the Johnson-Cook model [17]. Xiao et al. performed ballistic resistance of double layered 2024-T351 aluminium alloy plate against blunt projectiles and the modeling was carried out in ABAQUS/Explicit utilizing Johnson Cook plastic model [18]. Santha Rao and Shashank Simhadri proposed an improvement mechanism of aluminium alloy 5083 composites with hybrid reinforcement particles through friction stir process [19]. Bala et al. studied the bullet impact behavior of bamboo wall panels and found bamcrete panels have depth bullet penetration and energy absorption capacity compared to RCC [20]. Wu et al. performed anti-blast properties of 6063-T5 aluminium alloy with circular tube coated with polyurea elastomer and they conclude that polyurea cannot be directly applied. Mechanical performance of polyurea materials was studied while performing Quasi-static compression and tensile experiments [21]. Bagwe et al. studied numerical analysis of armour steel and aluminium alloy impacted by armourpiercing bullet and their ballistic performances were compared using ANSYS and the material model was developed utilizing the Johnson-Cook material model [22]. Several studies worldwide have been carried out on various materials and their performance-development techniques to meet the engineering requirement [23-31]. This leads to increasing demand for accurate, robust, and efficient numerical models to analyze the mechanical response of engineering structures under dynamic loading conditions.
1.3. Research Gap. From the available literature, there is minimal information regarding the critical velocity application essentially to evaluate perforation to ensure the reliability of the helmet impact of the soldier. According to the author's knowledge, it is found that none of the researchers focused on the comprehensive analysis of mechanical behavior of plastic strength, fracture, numerical analysis, and experimental application to high-velocity bullet impact. Thus, this research work aims to increase the knowledge of material's response application to the high-velocity impact that can be used in arms-ammunition, aviation, marine, automobile, and home appliances.

1.4. Research Objective. With the massive use and importance of Al6061 alloy, this research has been focused to elaborate on the detailed material behavior and comparative analysis has been carried out. The following are the main objectives of this study:

(i) To evaluate the comprehensive analysis of mechanical behavior under large stress-strain deformation and failure responses of the Al6061 alloy over a wide range of strain-rates such as $1 \times 10^{-3} \mathrm{~s}^{-1}$, $1 \times 10^{3} \mathrm{~s}^{-1}, 2 \times 10^{3} \mathrm{~s}^{-1}$, and $3 \times 10^{3} \mathrm{~s}^{-1}$ under room temperature to an elevated temperature $100^{\circ} \mathrm{C}$ and $200^{\circ} \mathrm{C}$, respectively.

(ii) To determine the Johnson-Cook strength and fracture constants of an Al6061 alloy utilizing the Johnson-Cook constitutive model equation.

(iii) To determine the critical perforation velocity of an Al6061 alloy flat plate, when the bullet is fired with flat-nosed normal to the center of the plate.

(iv) To validate critical perforation velocity with the comparisons of a high-velocity bullet impact experimental acquisition results with ABAQUS/CAE numerical simulation results.

1.5. Novelty of the Study. The novelty of the study includes comprehensive mechanical behavior, evaluation of Johnson-Cook strength, fracture constants, and critical perforation velocity of $2 \mathrm{~mm}$ thickness of Al6061 alloy. OriginProV2017 software was used to obtain Johnson-Cook constants and ABAQUS/CAE to model the impact and analyze critical perforation velocity. Moreover, the numerical simulation has been compared with the experimental results to validate the critical perforation velocity. To the best of our knowledge, this is the first attempt in the literature.

1.6. Organization of the Study. The organization of the study is ordered as follows: Section 1 presents the Al6061 alloy background and literature which supports the ideas of the proposed research. As a result of the theory of machines in Section 2, an adequate theory of Split Hopkinson Pressure Bar is discussed and some relevant research in the literature has been reported that the Johnson-Cook model equation benefits accuracy and reliability compared to other model equations in the determination of Johnson-Cook strength 
and fracture constants. Also, a detailed experimental setup of high-velocity bullet impact is covered in the same section. Section 3 presents the method of sample preparation and method to determine Johnson-Cook strength and fracture parameters. The obtained constant parameters have been used to perform numerical simulation analysis utilizing ABAQUS/CAE software. In Section 4, to contribute to a fair comparative study, the results and observations were carried out to compare numerical simulation results with experimental results for the validation. Finally, Section 5 reports the main conclusions and recommendations.

\section{Johnson-Cook Model and High- Velocity Impact}

2.1. Theory of the Split Hopkinson Pressure Bar (SHPB). In 1913, Bertram Hopkinson introduced a technique to measure the peak pressure developed during a high strainrate deformation event. A Kolsky bar, also widely known as a Split Hopkinson Pressure Bar (SHPB) [32], consists of two long slender bars that are closely sandwiched to a short cylindrical specimen between them. By striking the end of one bar, a compressive stress wave shall be generated and will immediately traverse across the stricken bar and reach at one end of the specimen. The wave shall be partially reflected and transverse back to the impact end. The remainder of the wave shall then go through the specimen and into the second bar causing the irresponsible plastic deformation on the specimen. It can be observed that the reflected and transmitted waves are proportional to the specimen's strainrate and stress, respectively. The specimen stain can be determined by integrating the strain-rate [33-35]. By monitoring the strains in the two bars, the specimen stressstrain properties can be calculated out which is depicted in Figure 1.

\subsubsection{SHPB 3 Assumptions}

(a) One-Dimensional Stress Wave Assumption. The bar's cross-section must be kept flat, with a uniform distribution of axial stresses solely in the section. Therefore, the motion variable in the bar includes the displacement $(u)$, the particle velocity $(V)$, the stress $(\sigma)$, and strain $(\varepsilon)$ as a function of the axial coordinate $x$ and the time $(t)$. It concludes that the diameter of the bar be sufficiently small relative to its length so that the lateral inertia effect can be ignored.

(b) Stress-Strain Independent Assumption. The stress of the bar is only a single-valued function of the strain, i.e., the strain-rate effect of the bar is ignored.

(c) Strain Distribution of the Specimen along the Length of Uniform. During the loading process, the internal stress and strain of the specimen are evenly distributed in the longitudinal directions. The average strain of the whole specimen in the length is approximated as the strain in the specimen, i.e., the length of the specimen be sufficiently short and the time of passage of the stress wave through the specimen much less than the width of the loading pulse leaving the specimen in a uniformly compressed state.

The transmission of deformation energy in the specimen as a transmitted wave and the remaining energy will be reflected in the form of a reflective wave. During the deformation process, the pulse signal is recorded by a strain gauge which is attached at the middle of both the rods, and strain-rate, stress, and strain felt by the specimen during the experiment can be evaluated. The average engineering stress on the specimen can be calculated using the following formula [36]:

$$
\sigma_{s}(t)=\frac{P_{1}(t)+P_{2}(t)}{2 A_{s}},
$$

where $P_{1}(t)$ and $P_{2}(t)$ are the pressure of the rods and $A_{s}$ is the initial cross-sectional area of the specimen. Assume that the pressure bar's Young's modulus, velocity, and crosssectional area are $E, C_{0}$, and $A_{o}$ of the incident wave $\varepsilon_{I}(t)$ and transmitted wave $\varepsilon_{R}(t)$, respectively.

According to Wang Li-li, elastic wave for one dimension stress [37].

$$
\begin{aligned}
& P_{1}(t)=E A_{0}\left[\varepsilon_{I}(t)+\varepsilon_{R}(t)\right], \\
& P_{2}(t)=E A_{0} \varepsilon_{T}(t) .
\end{aligned}
$$

Substituting (2) and (3) in equation (1) can be written as follows:

$$
\sigma_{s}(t)=\frac{1}{2} E\left(\frac{A_{0}}{A_{s}}\right)\left[E_{I}(t)+E_{R}(t)+E_{T}(t) .\right.
$$

The strain-rate in the specimen is given by

$$
\dot{\varepsilon}_{s}(t)=\frac{V_{1}(t)-V_{2}(t)}{I_{s}},
$$

where $V_{1}(t)$ and $V_{2}(t)$ are the particles end face velocity of the incident and transmitted bar and $I_{s}$ is the original length of the specimen. Furthermore, it can be written as follows:

$$
\begin{aligned}
& V_{1}(t)=C_{0}\left[\varepsilon_{1}(t)-\varepsilon_{2}(t)\right], \\
& V_{2}(t)=C_{0} \varepsilon_{T}(t) .
\end{aligned}
$$

Substituting (5) and (6) in (4) can be written as follows:

$$
\dot{\varepsilon}_{s}(t)=\frac{C_{0}}{I_{s}}\left[\varepsilon_{I}(t)-\varepsilon_{R}(t)-\varepsilon_{T}(t)\right]
$$
follows:

Integrating (7) will give the average engineering strain as

$$
\varepsilon_{s}(t)=\frac{C_{0}}{I_{s}} \int_{0}^{t} \int_{0}^{t}\left[\varepsilon_{I}(t)-\varepsilon_{R}(t)-\varepsilon_{T}(t)\right] \mathrm{d} t .
$$

Thus, summarizing the SHPB three assumptions can be further simplified as follows: 


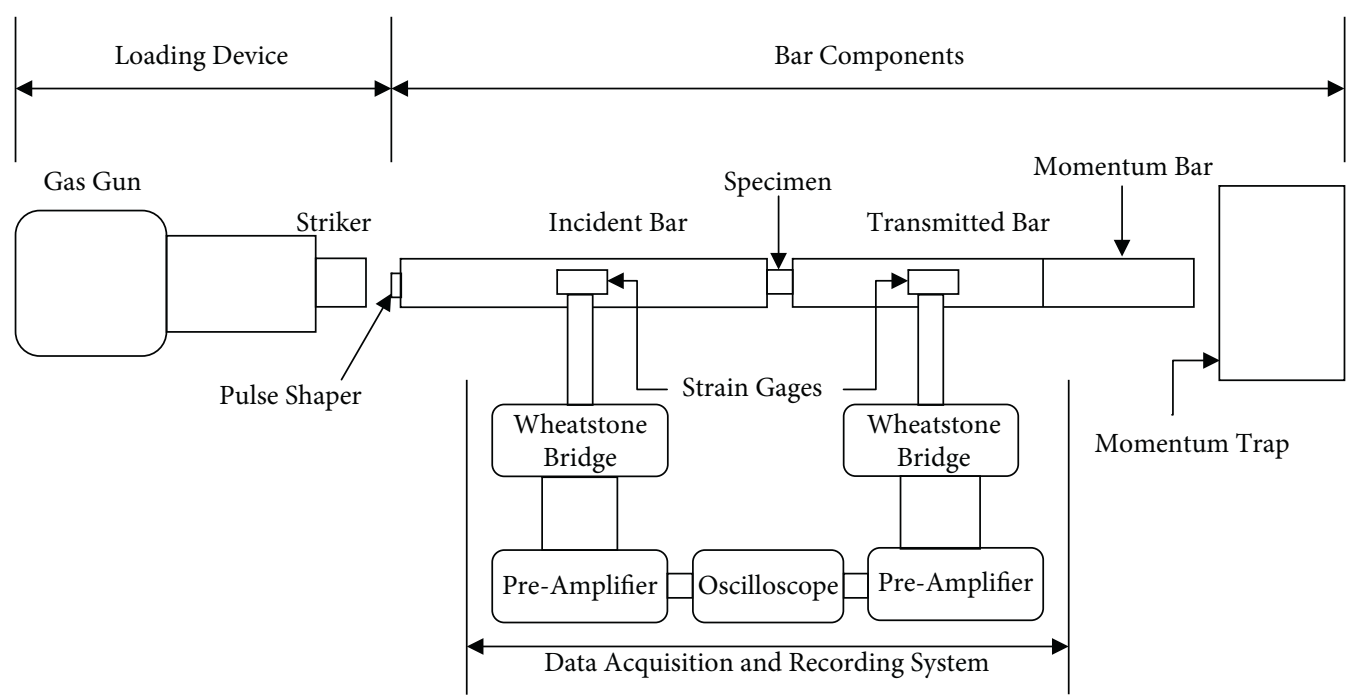

FIGURE 1: Schematic of the SHPB machine.

$$
\begin{gathered}
\sigma_{s}(t)=\frac{1}{2} E\left(\frac{A_{0}}{A_{s}}\right)\left[\varepsilon_{I}(t)-\varepsilon_{R}(t)-\varepsilon_{T}(t)\right], \\
\dot{\varepsilon}_{s}(t)=\frac{C_{0}}{I_{s}}\left[\varepsilon_{I}(t)-\varepsilon_{R}(t)-\varepsilon_{T}(t)\right], \\
\varepsilon_{s}(t)=\frac{C_{0}}{I_{s}} \int_{0}^{t} \int_{0}^{t}\left[\varepsilon_{I}(t)-\varepsilon_{R}(t)-\varepsilon_{T}(t)\right] \mathrm{d} t .
\end{gathered}
$$

The stress uniformity of the specimen is assumed to be $P_{1}(t)=P_{2}(t)$, and $\varepsilon_{I}(t)+\varepsilon_{R}(t)=\varepsilon_{T}(t)$. The SHPB is the most commonly used experimental technique for the determination of the dynamic compressive behavior of the materials at higher strain-rates such as $1 \times 10^{3} \mathrm{~s}^{-1}$, $2 \times 10^{3} s^{-1}$, and $3 \times 10^{3} s^{-1}$. The striker bar is fired at high speed to collide with the incident bar creating an incident strain pulse $\left(\varepsilon_{I}\right)$, which propagates along the bar until it reaches the specimen. At that point, acoustic impedance mismatches between bar and specimen materials, resulting in a portion of the pulse reflecting along the incident bar producing a strain $\left(\varepsilon_{R}\right)$; during the process some of the pulses are transmitted through the specimen and into the transmitter bar with strain $\left(\varepsilon_{T}\right)$. The engineering stress $(\bar{\sigma})$, strain-rate $(\dot{\varepsilon})$, and strain $(\varepsilon)$ experienced by the specimen can be further simplified from equations (9), (10), and (11) as follows:

$$
\begin{aligned}
& \sigma_{s}(t)=E\left(\frac{A_{0}}{A_{s}}\right) \cdot \varepsilon_{T}(t), \\
& \dot{\varepsilon}_{s}(t)=\frac{2 C_{0}}{I_{s}} \cdot \varepsilon_{R}(t), \\
& \varepsilon_{s}(t)=\frac{2 C_{0}}{I_{s}} \int_{0}^{t} \varepsilon_{R}(t) \mathrm{d} t .
\end{aligned}
$$

Hence, engineering stress and strain transformed to calculate true stress and true strain of the sample during the experiment is given by

$$
\begin{aligned}
& \bar{\sigma}=\sigma(1+\varepsilon), \\
& \bar{\varepsilon}=\log (1+\varepsilon) .
\end{aligned}
$$

2.2. Johnson-Cook Constitutive Equation. Johnson and Cook's model was developed during the 1980s to study the impact, ballistic penetration, and explosive detonation problems. A constitutive model is primarily intended for computations, and it is recognized that more complicated models can describe the material behavior accurately. The constitutive equation developed by Johnson-Cook also known as Johnson and Cook model carried out to evaluate the high rate of deformation during the simulation. The model has proven to be very popular and has been used extensively in national laboratories, military laboratories, and private industry to study material behaviors under conditions of large strain and a wide range of strain-rates and temperatures [38, 39].

There are many computer codes and constitutive models depicted in Table 1 for the analysis accounting for large strains, high strain-rates, and thermal softening, which can generalize strength and fracture mechanism [40-43].

The context of dynamic modeling requires the generalized constitutive equations which can describe the ratedependent inelastic behavior of metals as functions of strains, strain-rates, and temperature. Due to simplicity and good results in high dynamic regions, many numerical simulations literature is based on the Johnson-Cook material model [44-46].

2.2.1. Johnson-Cook Strength Model. The JC model consists of two parts. The first part describes material plastic flow stress that varies with strain, strain-rate, and temperatures. According to Johnson and Cook, the model for the Von Mises flow stress, $\sigma$, is expressed as [44]

$$
\sigma=\left(A+B\left(\varepsilon^{p}\right)^{n}\right)\left(1+C \log \left(\dot{\varepsilon}^{*}\right)\right)\left(1-\left(T^{*}\right)^{m}\right),
$$


TABLE 1: Types of constitutive equations.

\begin{tabular}{|c|c|c|}
\hline Authors & Equation & Parameters \\
\hline $\begin{array}{l}\text { Ludwik (1909) } \\
\text { Holloman }(1945)\end{array}$ & $\sigma=\sigma_{0}+K \varepsilon^{n}$ & $\sigma_{0}, \mathrm{~K}, n=$ constants \\
\hline Holloman (1945) & $\sigma=K \varepsilon^{n}$ & $\mathrm{~K}, n=$ constants \\
\hline Swift (1952) & $\sigma=K\left(\varepsilon_{1}+\varepsilon\right)^{n}$ & $\begin{array}{c}\mathrm{K}, n=\text { constants } \\
\varepsilon_{1}=\text { pre-deformation }\end{array}$ \\
\hline Voce (1948) & $\sigma=\sigma_{0}-\left(\sigma_{0}-\sigma_{1}\right) \exp (-n \varepsilon)$ & $\begin{array}{c}\sigma_{0}, \sigma_{1}, n=\text { constant } \\
\sigma_{0}=\text { yield stress }\end{array}$ \\
\hline Tome et al. (1984) & $\sigma=\sigma_{0}+\left(\sigma_{1}+\theta_{1} \varepsilon\right)\left(1-\exp \left(\theta_{0} \varepsilon / \sigma_{1}\right)\right)$ & $\begin{array}{c}\sigma_{1}=\mathrm{d} \sigma / \mathrm{d} \varepsilon=\text { constants } \\
\theta_{0} \text { and } \theta_{1}=\text { workhard. coef. }\end{array}$ \\
\hline Ludwingson (1971) & $\sigma=K_{1} \varepsilon^{n_{1}}+\exp \left(K_{2}+n_{2} \varepsilon\right)$ & $K_{1}, K_{2}, n_{1}, n_{2}=$ constants \\
\hline Gladman et al. (1970) & $\sigma=\sigma_{0}+K_{1} \ln \varepsilon+K_{2} \varepsilon$ & $\sigma_{0}, K_{1}, K_{2}=$ constants \\
\hline El-Magd and Troost (1997) & $\sigma=K \varepsilon^{n}\left(\dot{\varepsilon} / \dot{\varepsilon}_{0}\right)^{m}$ & $K, n, m, \dot{\varepsilon}_{0}=$ constants \\
\hline El-Magd (1997) & $\sigma=\left[K_{1}\left(K_{2}+\varepsilon\right)^{n}+\eta \dot{\varepsilon}\right] \exp \left(-\beta\left(T-T_{0}\right) / T_{m}\right)$ & $K_{1}, K_{1}, n, \eta, \beta=$ constants \\
\hline Reiff et al. (1986) & $\sigma=\left[K_{1}+K_{2}(\dot{\varepsilon} / \varepsilon)^{\frac{1}{m}}+K_{3} \sqrt{\varepsilon}\right]$ & $K_{1}, K_{2}, K_{3}, m=$ constants \\
\hline Johnson and cook (1983) & $\sigma=\left(A+B\left(\varepsilon^{p}\right)^{n}\right)\left(1+C \log \left(\dot{\varepsilon}^{*}\right)\right)\left(1-\left(T^{*}\right)^{m}\right)$ & $\begin{array}{c}A, B, n, C, m=\text { constants } \\
D, P=\text { constants }\end{array}$ \\
\hline Cowper Symonds & $\sigma_{y}=\left[\sigma_{0}+\beta E_{p} \varepsilon_{\mathrm{eff}}^{p}\right]\left[1+\left(\dot{\varepsilon}_{p} / D\right)^{1 / p}\right]$ & $\sigma_{y}=$ initial yield strength \\
\hline Zerilli and Armstrong (1987) & $\sigma=\sigma_{0}+K_{1}\left(\dot{\varepsilon}_{0} / \dot{\varepsilon}\right)^{-K_{3} T}+K_{2} / e^{-K_{4}} \varepsilon^{n}+K_{5} d^{-1 / 2}$ & $\begin{array}{l}E_{p}=\text { plastic nardening modulus } \\
\sigma_{0}, K_{1}, K_{2}, K_{3}, K_{4}, K_{5}, n, \dot{\varepsilon}_{0}=\text { constants }\end{array}$ \\
\hline
\end{tabular}

where $A, B, C, n$, and $m$ are material constants and are evaluated from an empirical fit of flow stress (as a function of strain, strain-rate, and temperatures).

Where $\varepsilon^{\mathbf{p}}$ is the equivalent plastic strain, $\dot{\varepsilon}^{*}=\varepsilon^{*} / \varepsilon_{0}$ is the dimensionless plastic strain-rate for $\dot{\varepsilon_{0}}=1 s^{-1}$ considered as reference strain-rate. And, $\left(T^{*}=T-T_{\text {room }} / T_{\text {melt }}-T_{\text {room }}\right)$ is nondimensional homologous temperature, where $T$ is the absolute temperature, $T_{\text {room }}$ is the room temperature, and $T_{\text {melt }}$ is the material melting temperature of the Al6061 alloy.

The first bracket of (14) represents the isothermal stress which is a function of strain $\dot{\varepsilon_{0}}=1 s^{-1}$ (reference strain-rate for convenience). The second bracket denotes the strain-rate effect and the third bracket accounts for the thermal effects.

2.2.2. Johnson-Cook Fracture Model. The second part describes the fracture model intended to show the relative effect of various parameters. It also attempts to account for path dependency by accumulating damage as the deformation proceeds. For high-rate deformation problems, it is assumed that an arbitrary percentage of the plastic work done during deformation produces heat in the deforming of the material. For most of the materials, $90-100 \%$ of the plastic work is dissipated as heat in the material [47]. Therefore, the temperature used in the above (14) is derived from the increase in temperature according to the following expressions [46]:

$$
\Delta T=\frac{\alpha}{\rho c} \int \sigma(\varepsilon) \mathrm{d} \varepsilon,
$$

where $\Delta T$ is the temperature increase, $\alpha$ is the $\%$ of plastic work transformed into heat, $c$ is the heat capacity, and $\rho$ is the density.

Fracture in the Johnson-Cook material model is derived from the following cumulative damage law as Refs. [46, 48

$$
D=\sum \frac{\Delta \varepsilon}{\varepsilon_{f}},
$$

where $\Delta \varepsilon$ is the increment of equivalent plastic strain which occurs during an integration cycle, and $\varepsilon_{f}$ is the equivalent strain to fracture under the current conditions of strain-rate, temperature, pressure, and equivalent stress. Fracture is then allowed to occur when $D=1.0$, for constant values of the variables $\left(\sigma^{*}, \dot{\varepsilon}^{*}, T^{*}\right)$, and for $\sigma^{*} \leq 1.5$.

The general expression for the strain at fracture is given by Ref. [46]:

$\varepsilon^{f}=\left(D_{1}+D_{2} \exp D_{3} \sigma^{*}\right)\left(1+D_{4} \log \varepsilon^{*}\right)\left(1+D_{5} T^{*}\right)$.

The dimensionless pressure-stress ratio is defined as $\sigma^{*}=\sigma_{m} / \bar{\sigma}$, where $\sigma_{m}$ is the average of the three normal stresses, and $\bar{\sigma}$ is the Von Mises equivalent stress. The dimensional strain-rate $\left(\dot{\varepsilon}^{*}\right)$ and homologous temperature $\left(T^{*}\right)$ are identical to those used in the Johnson-Cook strength model, and (17) $D_{1}, D_{2}, D_{3}, D_{4} \& D_{5}$ are the fracture constants. The expression in the first set of a bracket in (17) supports the hydrostatic tension pressure and triaxiality formation during the failure deformation path of Al6061 alloy during the experimental tension tests in three different notched specimens. The second set of bracket represents the effect of strain-rate, and the third set of bracket gives information about the effect of temperatures.

(1) Triaxiality Stress. The stress state is often a complex stress state, which is the collection of two and more than two basic deformations shown in Figure 2. To describe this complex stress state, the stress triaxiality follows the following expressions [49]:

$$
\begin{aligned}
R_{\sigma} & =\frac{\sigma_{m}}{\sigma_{e}} \\
& =\frac{\left(\sigma_{1}+\sigma_{2}+\sigma_{3}\right) / 3}{1 / \sqrt{2} \sqrt{\left(\sigma_{1}-\sigma_{2}\right)^{2}+\left(\sigma_{2}-\sigma_{3}\right)^{2}+\left(\sigma_{3}-\sigma_{4}\right)^{2}}}
\end{aligned}
$$

where $\sigma_{1}, \sigma_{2}, \sigma_{3}, \sigma_{m}$, and $\sigma_{e}$ are expressed as three principal stresses, hydrostatic pressure, and von Mises equivalent 


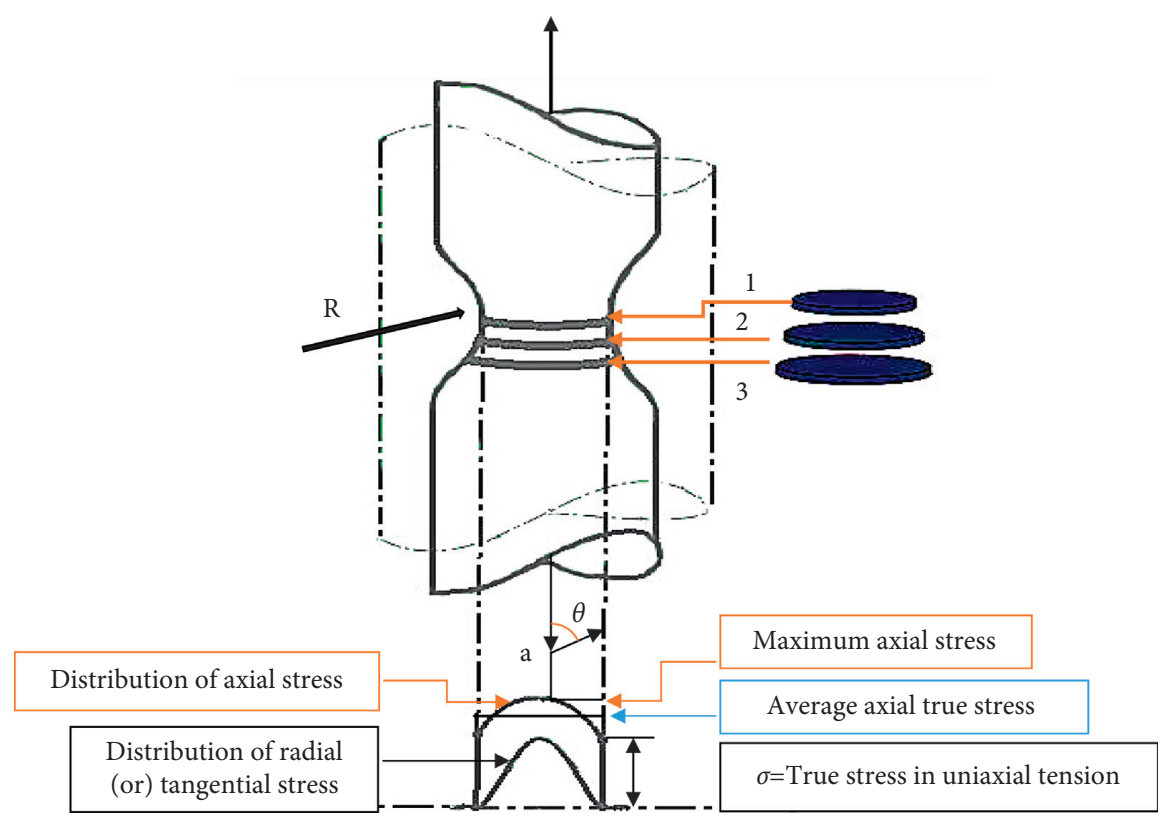

FIgURE 2: Triaxial stress in the notched specimen.

stress, respectively. The stress triaxiality is a dimensionless parameter, which reflects the degree of the constraint of the plastic deformation capacity of the material. The fracture mechanism of the Al6061 alloy material during the experiment is dominated by pore expansion and polymerization, leading to the local shear band and leading transformation. Uniaxial tensile (pull-up) stress triaxiality is $1 / 3$, for uniaxial compression, stress triaxiality is $-1 / 3$ and for pure torsion, the stress triaxiality is 0 .

Bridgman found a method for finding the true stressstrain relation assuming uniform strain distribution in the notched section and the stress equation of the specimen is presented as [48]

$$
\frac{\mathrm{d} \sigma_{r r}}{\mathrm{~d} r}+\frac{\sigma_{z z}-\sigma_{r r}}{\rho}+\frac{\sigma_{r r}-\sigma_{\theta \theta}}{r}=
$$

Assuming the notched curve is an arc, then the stress component of the notched specimen is given as

$$
\begin{gathered}
\sigma_{r r}=\sigma_{\theta \theta}=\sigma_{e} \log \left(1+\frac{a^{2}-r^{2}}{2 a R}\right), \\
\sigma_{z z}=\sigma_{e}\left[1+\log \left(1+\frac{a^{2}-r^{2}}{2 a R}\right)\right] .
\end{gathered}
$$

According to the definition of stress triaxiality, the formula of stress triaxiality and equivalent failure strain can be obtained as [50]

$$
\begin{aligned}
& R_{\sigma}=\frac{1}{3}+\log \left(1+\frac{a^{2}-r^{2}}{2 a R}\right), \\
& \varepsilon_{f}=2 \log \left(\frac{a_{0}}{a}\right),
\end{aligned}
$$

where $a$ and $R$ are minimum cross-sectional radius and radius of the notched radius, respectively, $r$ is the distance to the center of the cross-sectional, $a_{0}$ is the initial radius of the smallest cross-section, and $\varepsilon_{f}$ is the equivalent failure strain. The value of the triaxiality of stress is maximum at the smallest cross-section (i.e., $r=0$ ).

$$
R_{\sigma(\max )}=\frac{1}{3}+\log \left(1+\frac{a_{0}}{2 R_{0}}\right) .
$$

2.3. Experimental Setup of High-Velocity Bullet Impact. The bullet impact over flat Al6061 alloy was carried out utilizing the high-velocity bullet impact experimental setup to determine the critical perforation velocity. The working principle of the experimental setup is described in this section and the schematic of the experimental setup is shown in Figure 3.

A pneumatic gas gun is equipped with an air compressor in which air is compressed into the desired pressure and the bullet propels forward when the pressure valve is activated. The system consists of a $78 \mathrm{~mm}$ bore compressed air gun with a supporting compressor, instrumentation, and control system. The compressor system pumps air into the storage tank, and the air storage tank used for driving the gun is shown in Figure 4.

The bullet was held inside a wood sabot such that the sabot was trapped by a steel stopper reaching the end of the barrel allowing the bullet to continue its flight without any velocity loss as shown in Figure 5.

2.3.1. Target Description. The square aluminum plate $\left(205 \times 205 \times 2 \mathrm{~mm}^{3}\right)$ was sandwiched between 2 and 2 steel frames and 2-2 plastic layer frames, front and back. The steel frame and target specimen plate assembly were rigidly attached with support structure connected nut-bolts as shown in Figure 6. 


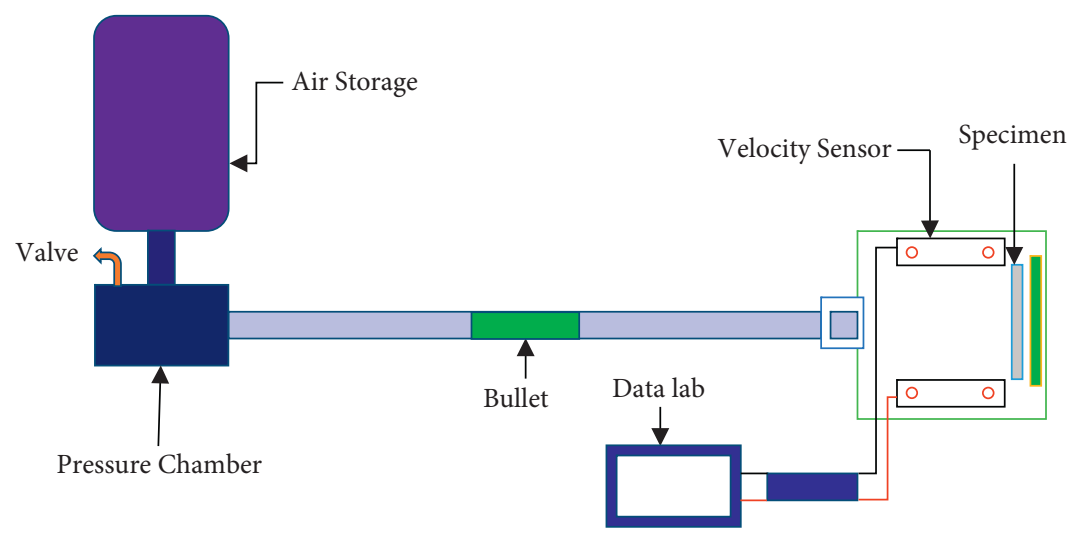

Figure 3: Schematic diagram of high-velocity bullet impact.
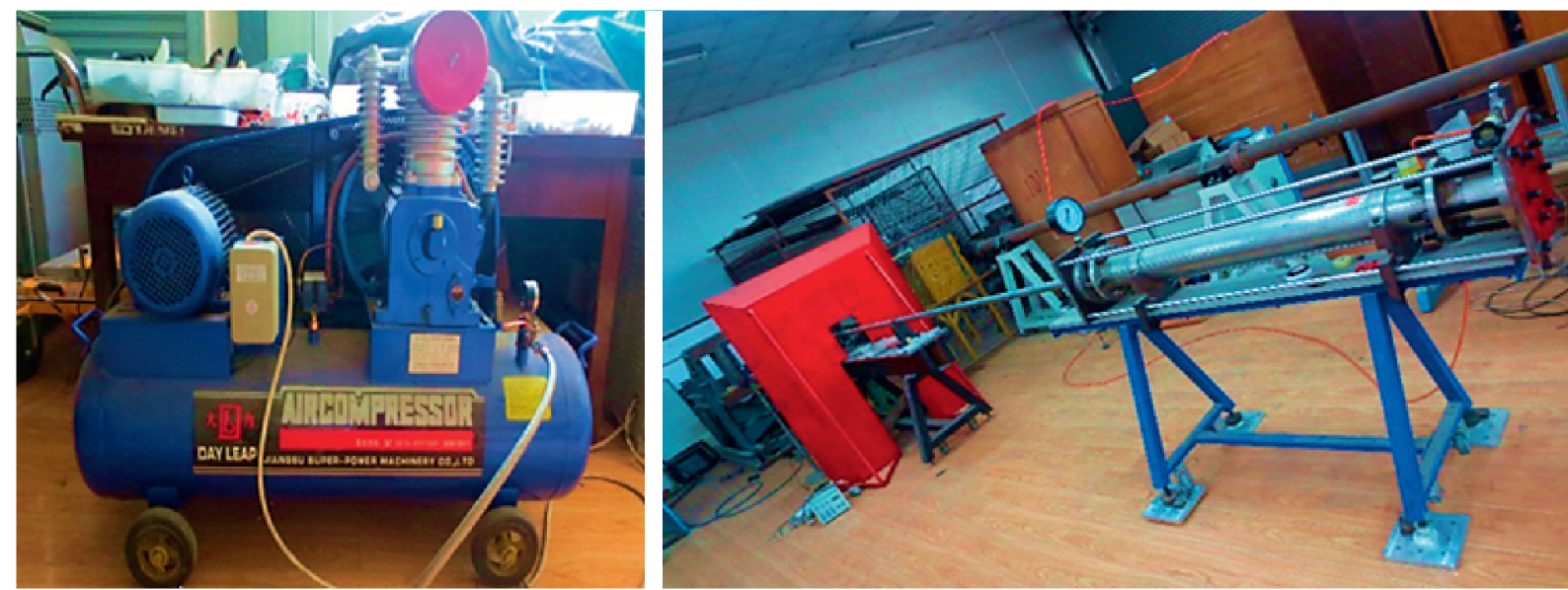

FIgURE 4: Air compressor with a driving tank system.
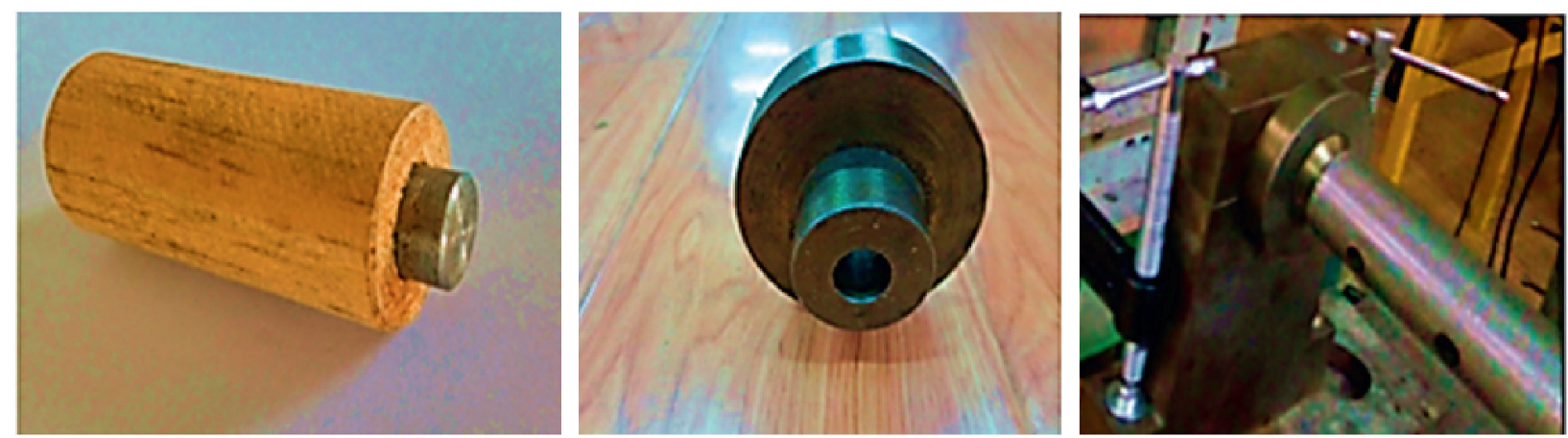

FIGURE 5: Sabot wooden stopper.

2.3.2. Velocity and Orientation Measurements. The velocity of the bullet was measured utilizing the projectile time-offlight technique in which two helium or neon laser beams are placed at the known distance across the muzzle of the sabot stripper and the target shown in Figure 7 . The distance between the laser beams and the elapsed time were used to calculate the velocity.

2.3.3. Data Acquisition. As the bullet impact over the flat plate process was very short, 3-4 ms, the high-speed data acquisition recorder was carried out to collect the strain data using super dynamic strain gauges and sensors. The schematic of the data acquisition setup is shown in Figure 8.

2.3.4. Measurement of Strains. The strain gauge was fixed at the back surface of the target plate to get the strain-time history during the bullet impact process. Three strain gauges were tightly stuck, i.e., bonded with glue to the target plate according to the pattern in which the center of the target was coinciding, as shown in Figure 9. The sensing element of the 

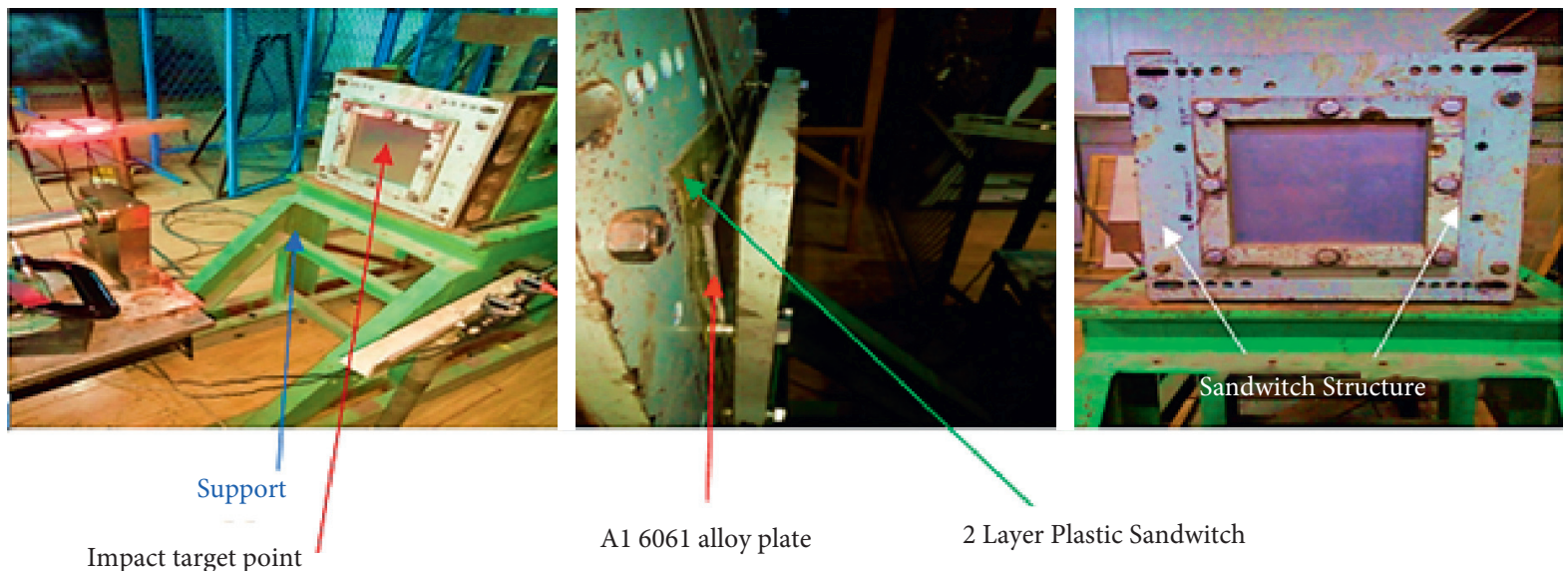

Figure 6: The Sandwich structure with support.
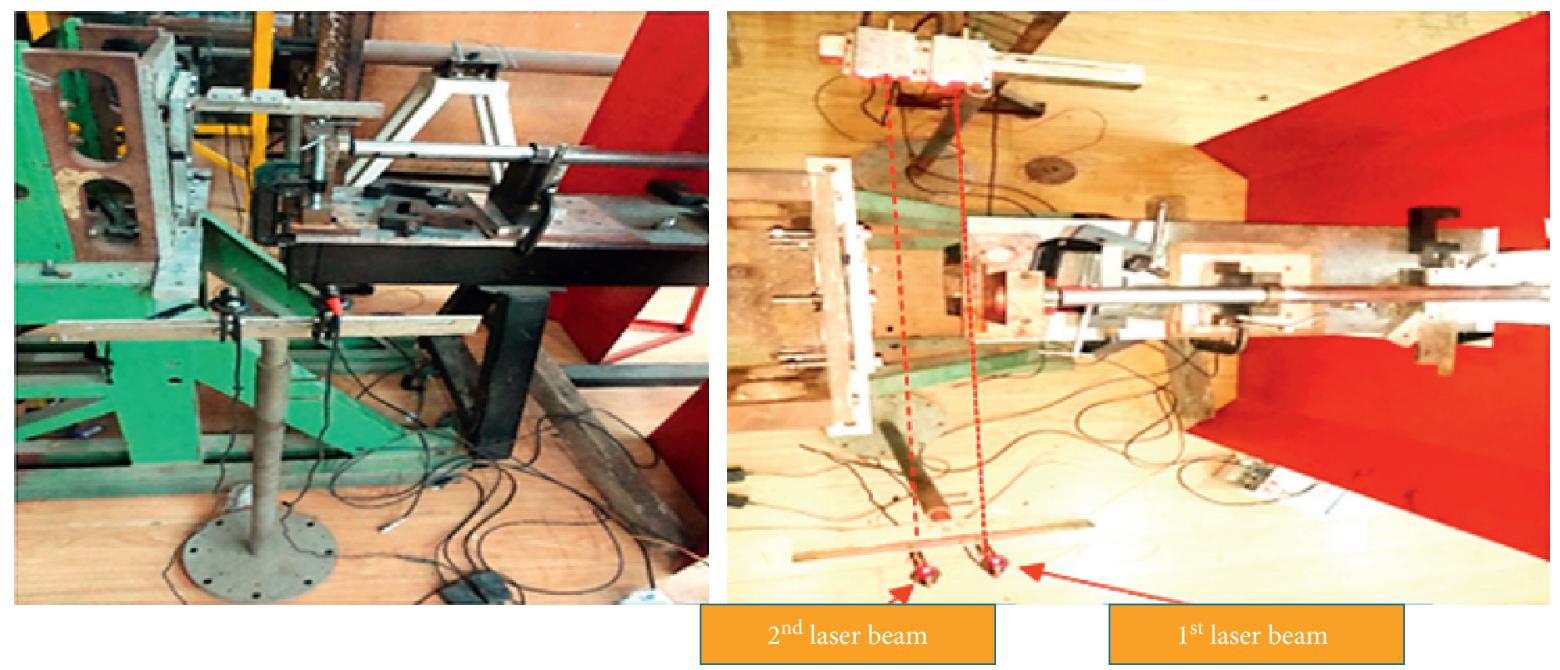

Figure 7: Velocity measurement setup before impact.

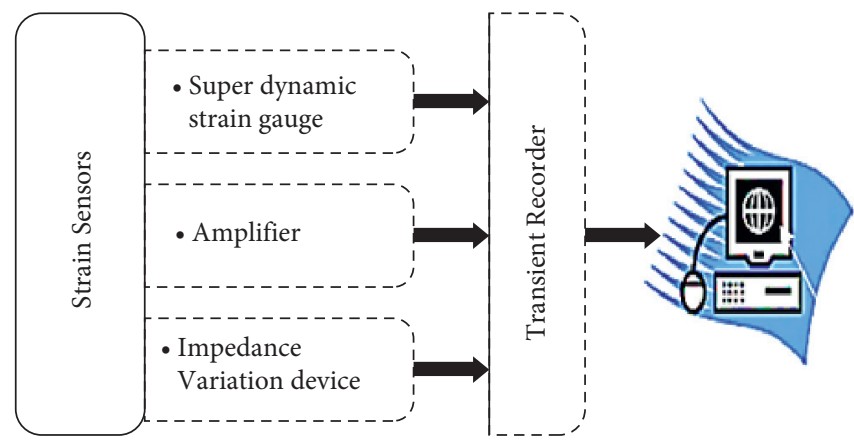

Figure 8: Schematic of the data acquisition process. 

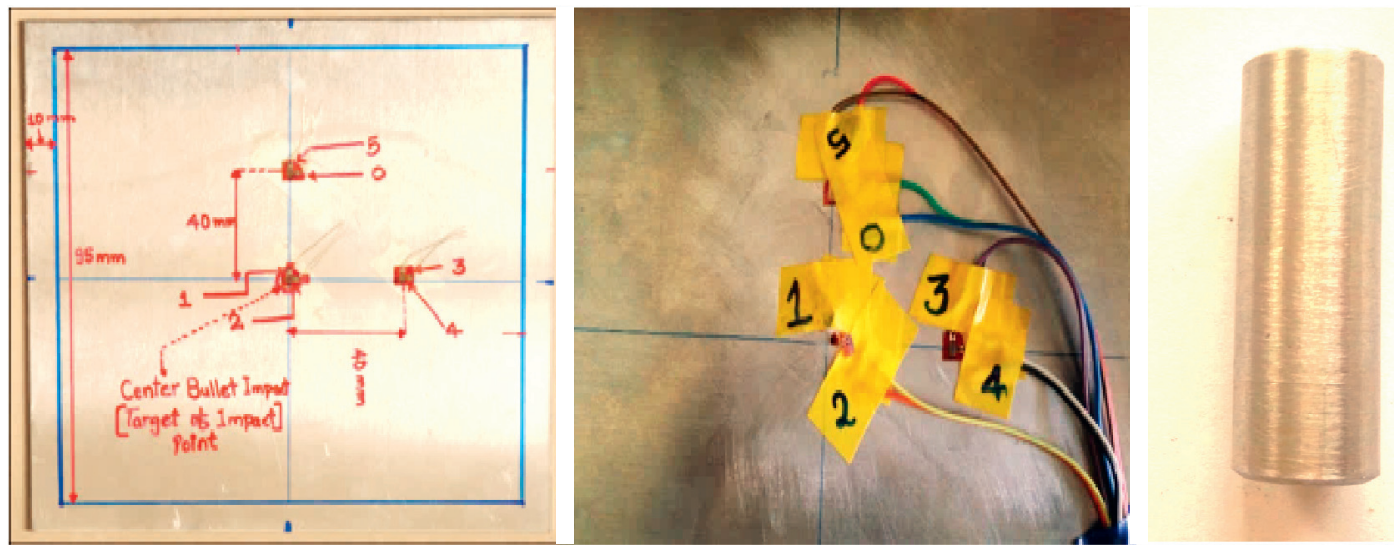

FIGURE 9: Strain gauges on the target specimen and real bullet.

strain gauge was made of copper-nickel foil and works on the principle of resistance change. The strain measurement system frequency response was set to $10 \mathrm{MHz}$ with strain gauges recording strains and voltage measuring in the range of $0-20000 \mu \varepsilon$, and $\pm 5 \mathrm{~V}$, respectively.

\section{Methodology}

The detailed methodology to validate the critical perforation velocity of the Al6061 alloy is illustrated in Figure 10.

3.1. Sample Preparation. To conduct the research, the various samples of Al6061 alloy were prepared to study comprehensive mechanical behavior. The quasi-static, quasi-dynamics, and high-velocity bullet impact tests were performed under a wide range of strain-rates as well as at elevated temperatures. Accordingly, experimental machines have been utilized to perform this research.

\subsubsection{Quasi-Static}

(1) Tensile Test. DNS-100 electronic universal testing machine shown in Figure 11 was utilized to determine the tensile mechanical behavior of Al6061 alloy at three different temperatures such as room temperature $20^{\circ} \mathrm{C}$, and elevated temperatures at $100^{\circ} \mathrm{C}$ and $200^{\circ} \mathrm{C}$, respectively.

For that, the smooth specimen of diameter $5.0 \mathrm{~mm}$, and three different notched specimens (notched diameter $1.5 \mathrm{~mm}, 2.0 \mathrm{~mm}$, and $2.5 \mathrm{~mm}$ ) were prepared, which are depicted in Figure 12, respectively. Mechanical behaviors of smooth and notched specimens have been studied experimentally, which are presented in Figures 13 and 14 of the appendix, respectively. To calculate failure strain during the tensile process, the data were recorded with the help of a high-speed camera for precise accuracy.

(2) Torsion Test. A dog-bone shape sample was prepared $\Phi 5.7 \times 14 \mathrm{~mm}$ for the torsion rate and twisting ability of the Al6061 alloy and the test was performed utilizing the computer-controlled DHW 1000 strain-rate machine, which is shown inFigure 15. The torsional response of the specimen is presented in Figure 16 of the appendix.

\subsubsection{Quasi-Dynamic}

(1) Split-Hopkinson Pressure Bar (SHPB). SHPB experimental setup was chosen for the compression test of Al6061 alloy and samples were prepared to maintain good polishing at both the ends whose dimension was made intentionally $\Phi 5 \times 5 \mathrm{~mm}$ before the experiment, which is shown in Figure 17. Figure 18 of the appendix presents the compression experimental behavior of the specimen at strain-rates of $1000 / \mathrm{s}, 2000 / \mathrm{s}$, and $3000 / \mathrm{s}$ at room temperature to an elevated temperature of $100^{\circ} \mathrm{C}$ and $200^{\circ} \mathrm{C}$, respectively.

(2) Split-Hopkinson Tension Bar (SHTB). The development of a method to test material to be in tension under high strain-rates (later called Split Hopkinson Tension Bar, SHTB) was introduced a decade later after the SHPB $[51,52]$. The progress in using SHTB was very slow due to difficulties inherent in sample design, load application, and data interpretation. Many arrangements have been used to apply a tension pulse to the specimen. The differences between them are inherent in the load application, sample design, and bars arrangements. To perform tension tests in the Al6061 alloy, the experimental setup was reconfigured. The SHTB tension experimental specimen size was manufactured $\Phi 3 \times 5 \mathrm{~mm}$, which is shown in Figure 19.

While performing this experimental test, proper alignment and positioning of the sample with grips are the most important because mismatch might create traction in pulse, impedance, and reflections in wave propagation. The specimen was necessary to fix at both the ends of the incident and transmitted bars and strain gauge transmits the generated tension traction pulse to the computer when a longer bolt head with input bar is used to drive a hollow tube striker with the same inner diameter and area. The tension responses of the specimen have been studied and experimental tests have been presented in Figure 20 of the appendix. 


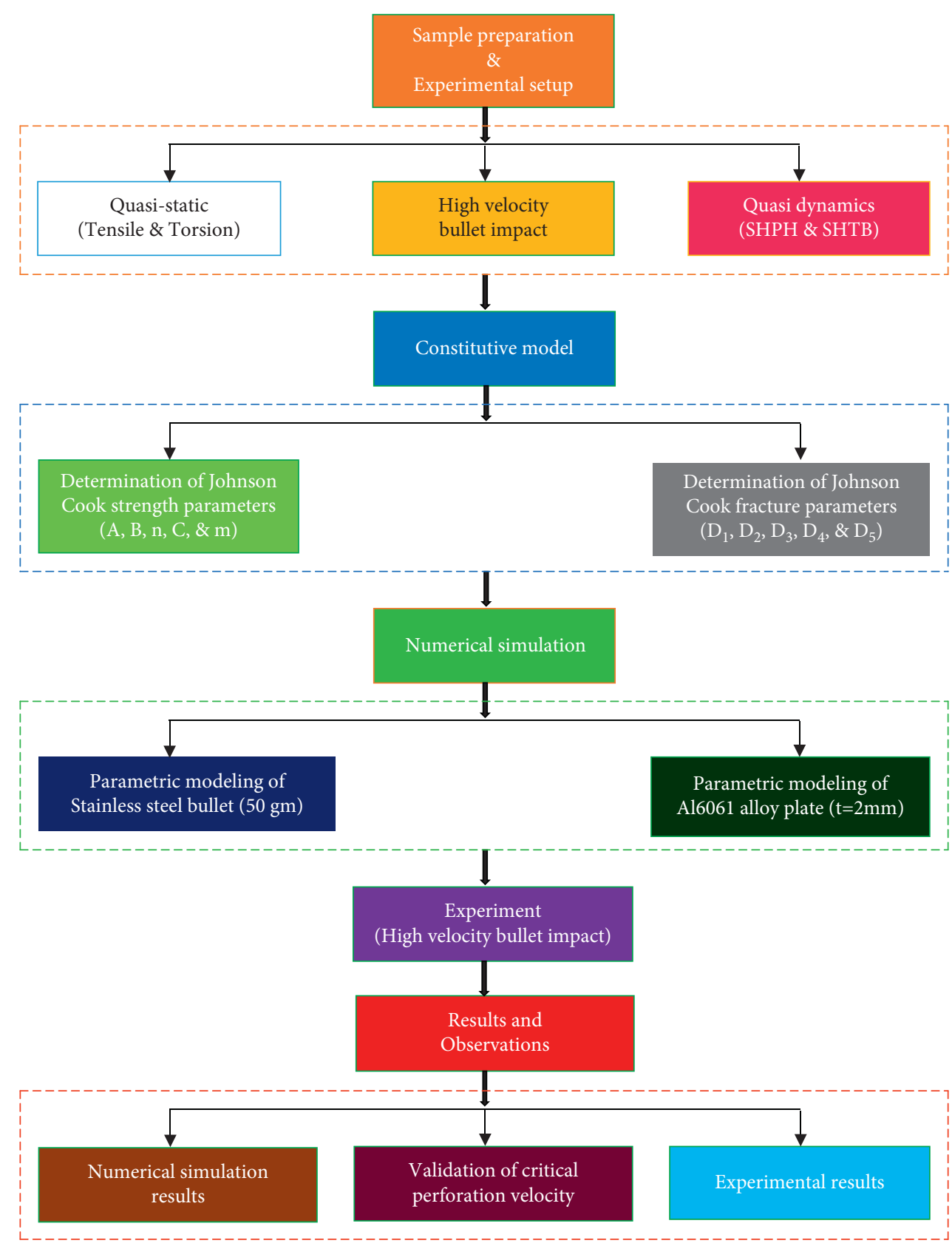

Figure 10: Flowchart illustrating the methodology.

3.1.3. High-Velocity Bullet Impact. A cylindrical bluntnosed bullet ( $45 \mathrm{~mm}$ length and $12 \mathrm{~mm}$ diameter) weighing $0.05 \mathrm{~kg}$ made of stainless steel is fired normally to the center of the Al6061 alloy specimen $\left(205 \times 205 \times 2 \mathrm{~mm}^{3}\right)$ to predict the critical perforation velocity. The strain gauge is fixed on the backside of the specimen at three different locations. One at the center of the impact region and two lateral sides apart from its exact center $40 \mathrm{~mm}$. The nomenclature was done as $(4,3),(0,5)$ for the two lateral sides while $(2,1)$ for the center impact region as shown in Figure 9. The strain pulse along the $X$ - and $Y$-axis is monitored and stored in a computercontrolled data acquisition system.

\subsection{Determination of Johnson-Cook Constant Parameters}

3.2.1. Johnson-Cook Strength Parameters. During the tension test, reference strain-rate $(\dot{\varepsilon})$ of $10^{-3} / \mathrm{s}$ was carried out for smooth (radius $5.0 \mathrm{~mm}$ ) and notched specimen (radii of $1.5 \mathrm{~mm}$, $2.0 \mathrm{~mm}, 2.5 \mathrm{~mm}$ ) to evaluate true stress-strain curve plotted under room temperature $\left(20^{\circ} \mathrm{C}\right)$, and at elevated temperatures of $100^{\circ} \mathrm{C}$ and $200^{\circ} \mathrm{C}$, respectively, to observe the material behavior of Al6061 alloy. An isolated furnace split-tube of $20 \mathrm{~cm}$ was utilized to maintain the elevated temperatures $100^{\circ} \mathrm{C}$ and $200^{\circ} \mathrm{C}$ to the specimen for observing the actual material behavior. Pure torsion and fracture morphology under reference strain-rate 


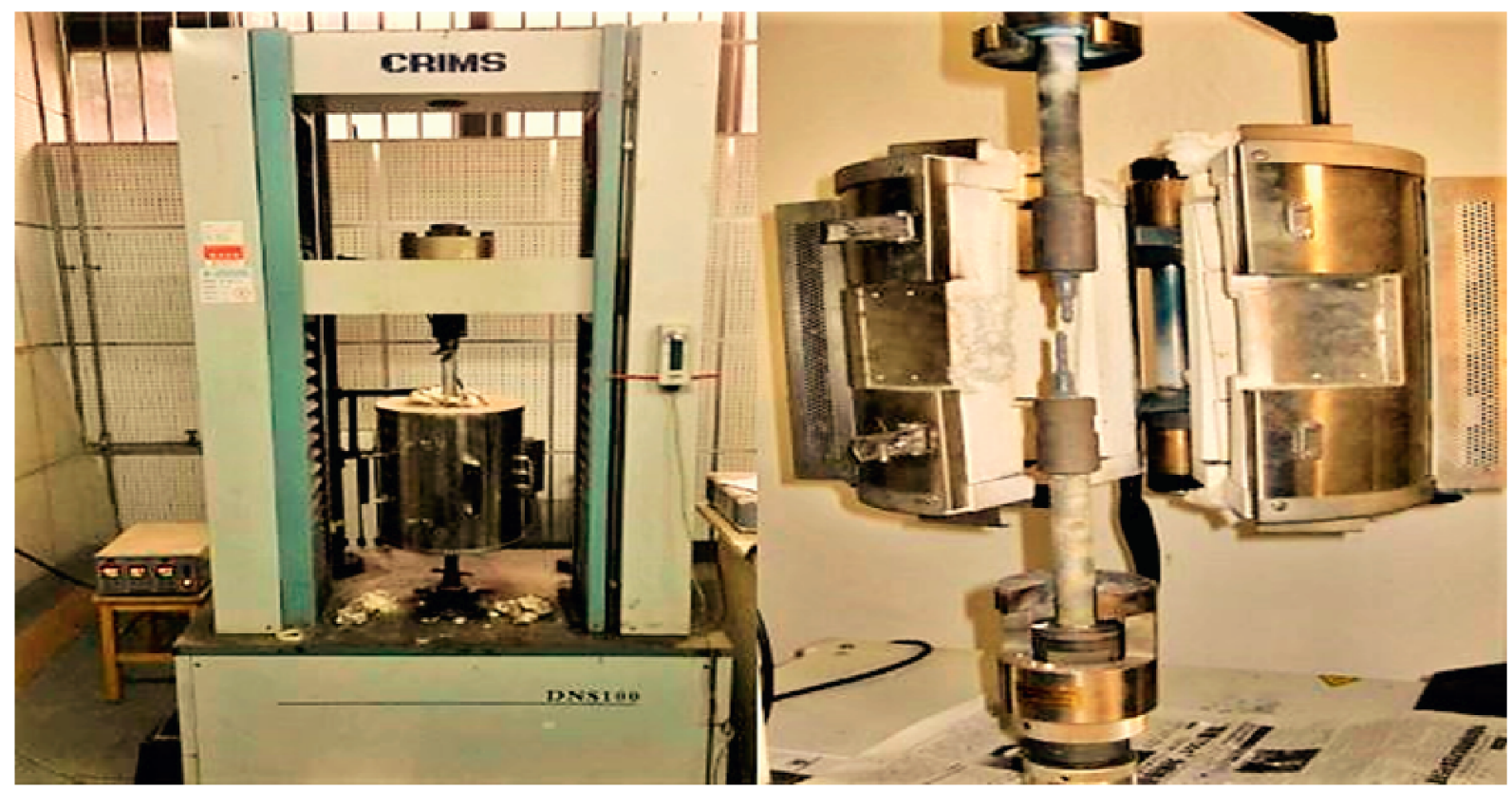

FIgURE 11: DNS100 tensile testing machine.
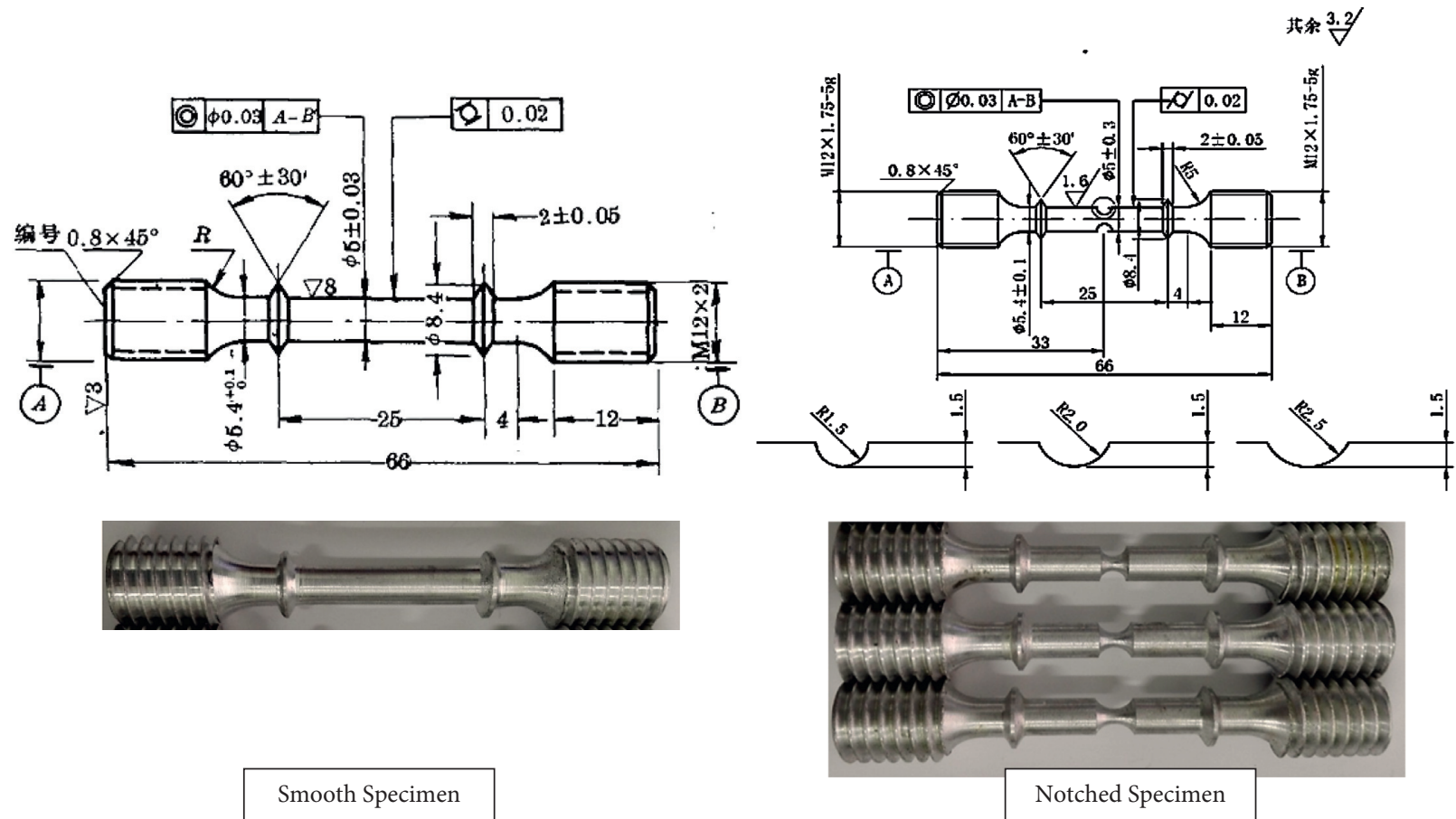

Smooth Specimen

Figure 12: Tensile test of Al6061 alloy for smooth and notched specimens.

have been studied in this work. Similarly, compression behaviors of Al6061 alloy have been studied dynamically with temperature variant in which 3 dynamic strain-rates $(\dot{\varepsilon})(1000 /$ s, 2000/s, and $3000 / \mathrm{s})$ were carried out at room temperature $\left(20^{\circ} \mathrm{C}\right)$ to elevated temperatures of $100^{\circ} \mathrm{C}$ and $200^{\circ} \mathrm{C}$, respectively.

(1) Determination of $A, B$, and $n$. Quasi-static experimental test of a smooth specimen whose radius was $5.0 \mathrm{~mm}$ carried out the tensile test at reference strain-rate $(\dot{\varepsilon})$ of $10^{-3} / \mathrm{s}$ under three different temperatures at room temperature $\left(20^{\circ} \mathrm{C}\right)$ to elevated temperature $100^{\circ} \mathrm{C}$ and $200^{\circ} \mathrm{C}$. Under this condition, equation (18) becomes

$$
\sigma=\left(A+B\left(\varepsilon^{p}\right)^{n}\right) .
$$

At reference strain-rate, true plastic stress-strain curves are plotted and the plastic strain was calculated by subtracting the elastic strain from the total strain. The average stress-strain value was calculated, as shown in Table 2 , and 


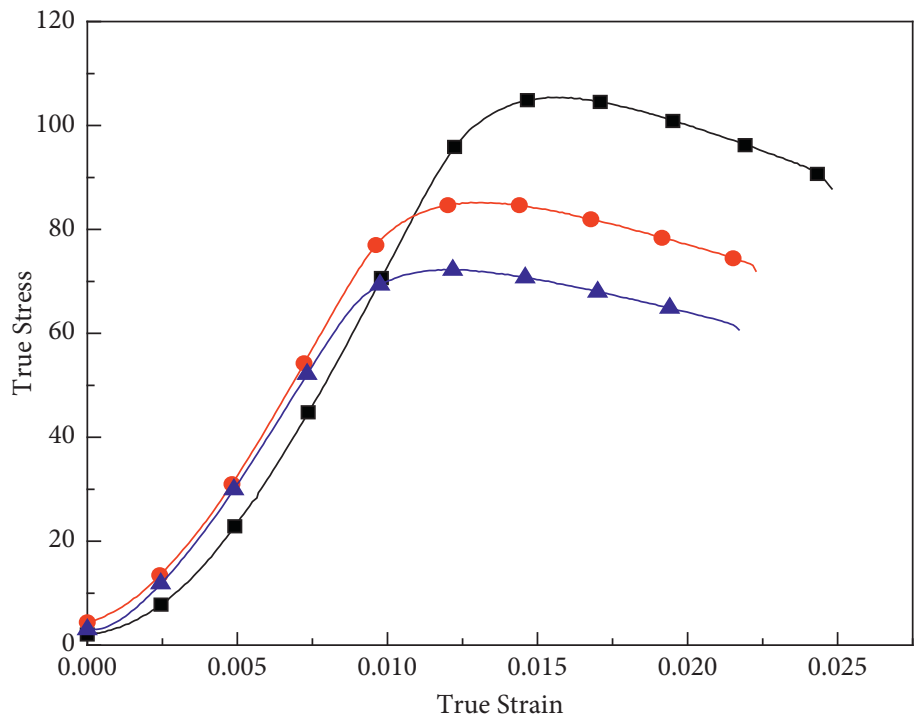

$\rightarrow$ Room Temperature

- 100 Degree celcius

- 200 Degree celcius

(a)

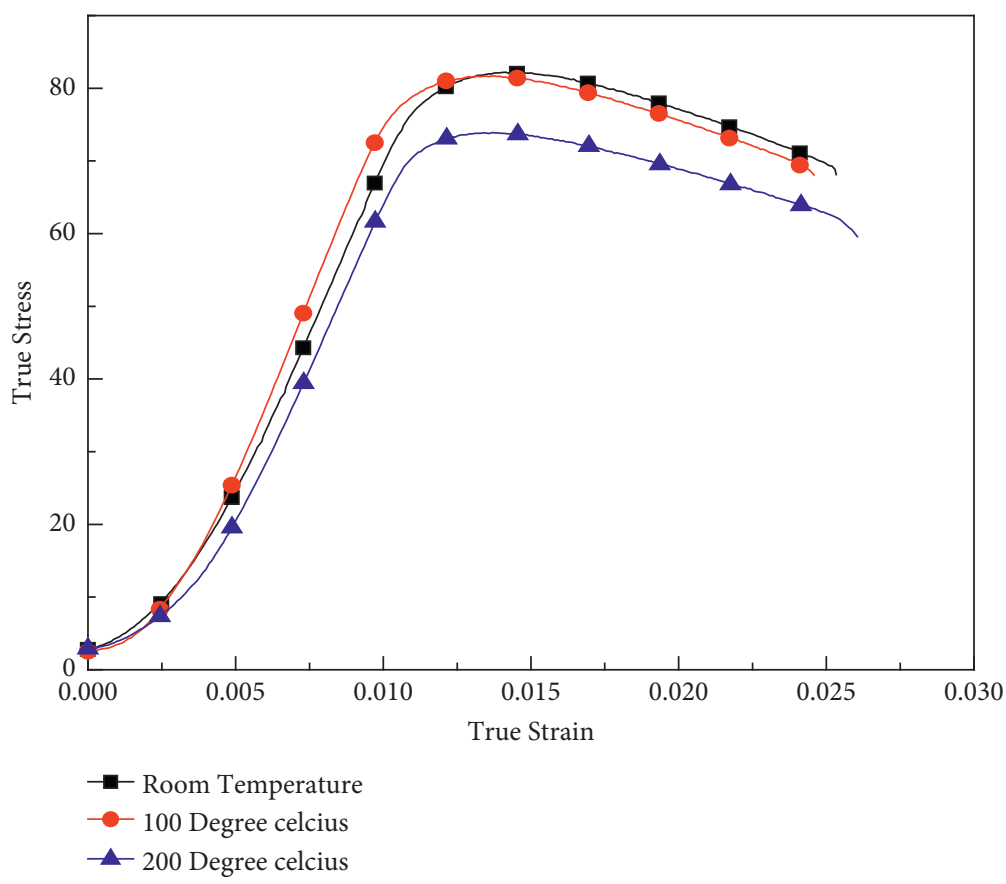

(b)

Figure 13: Continued. 


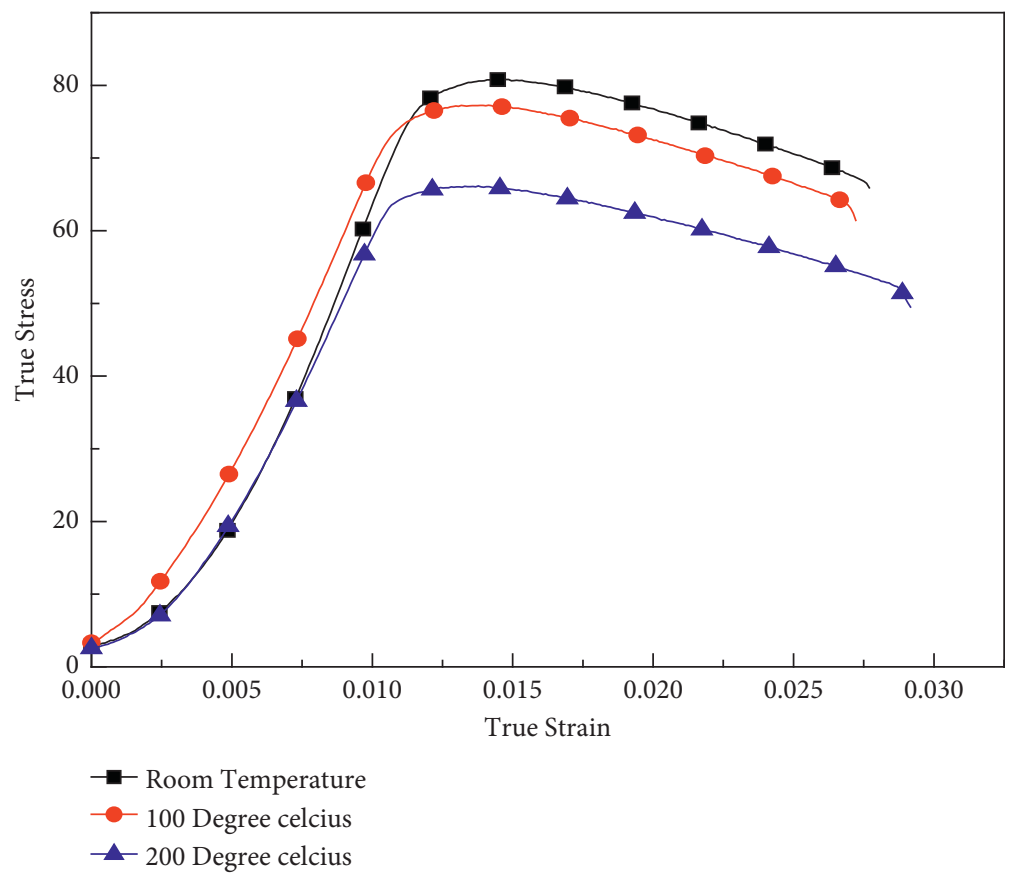

(c)

FIGURE 13: Notched specimens' mechanical response at three different temperatures. (a) Notched specimen with radii $1.5 \mathrm{~mm}$. (b) Notched specimen with radii $2.0 \mathrm{~mm}$. (c) Notched specimen with radii $2.5 \mathrm{~mm}$.

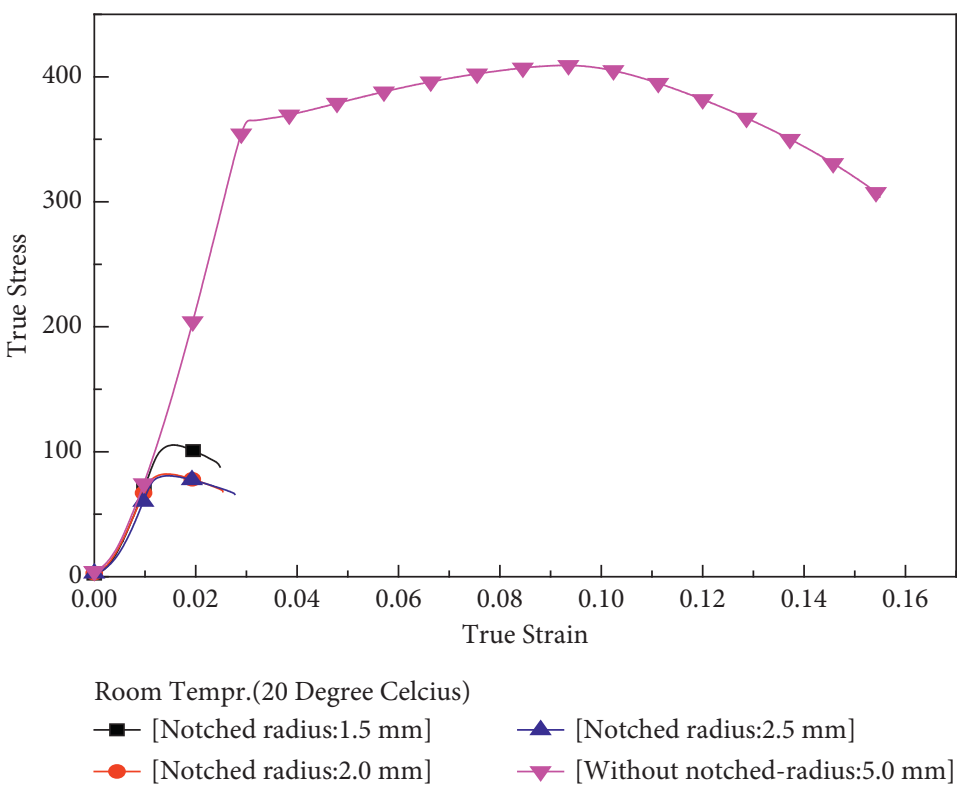

(a)

Figure 14: Continued. 


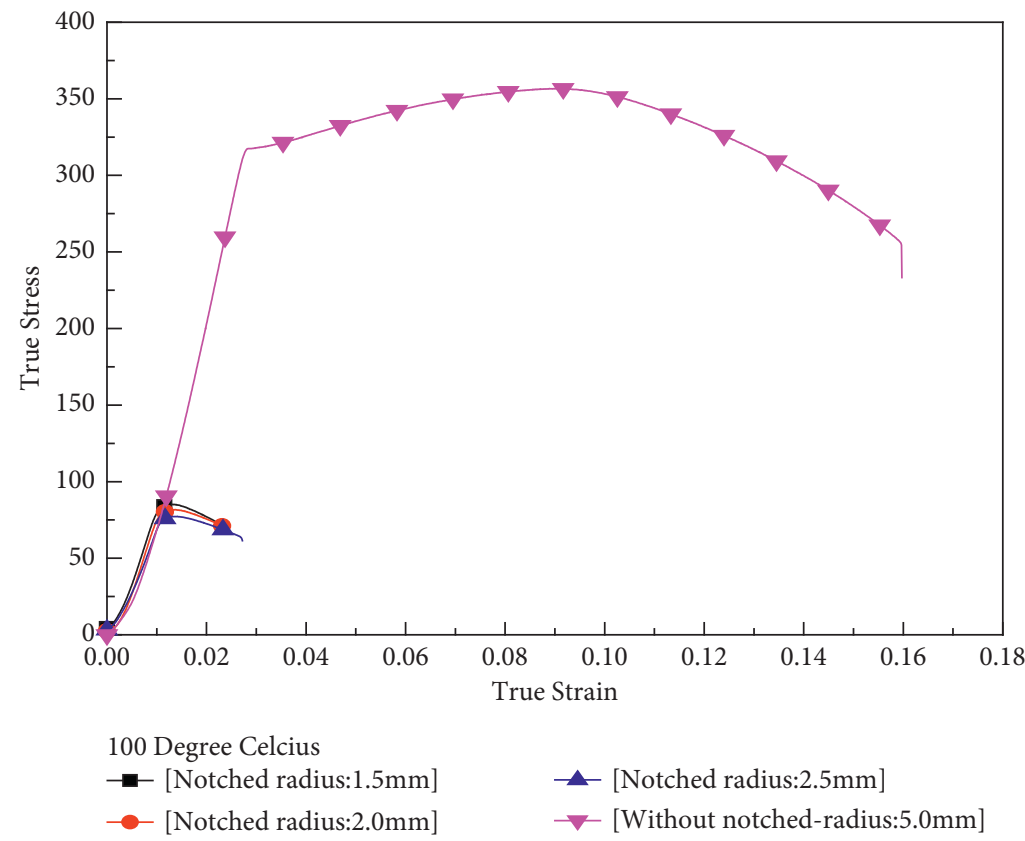

(b)

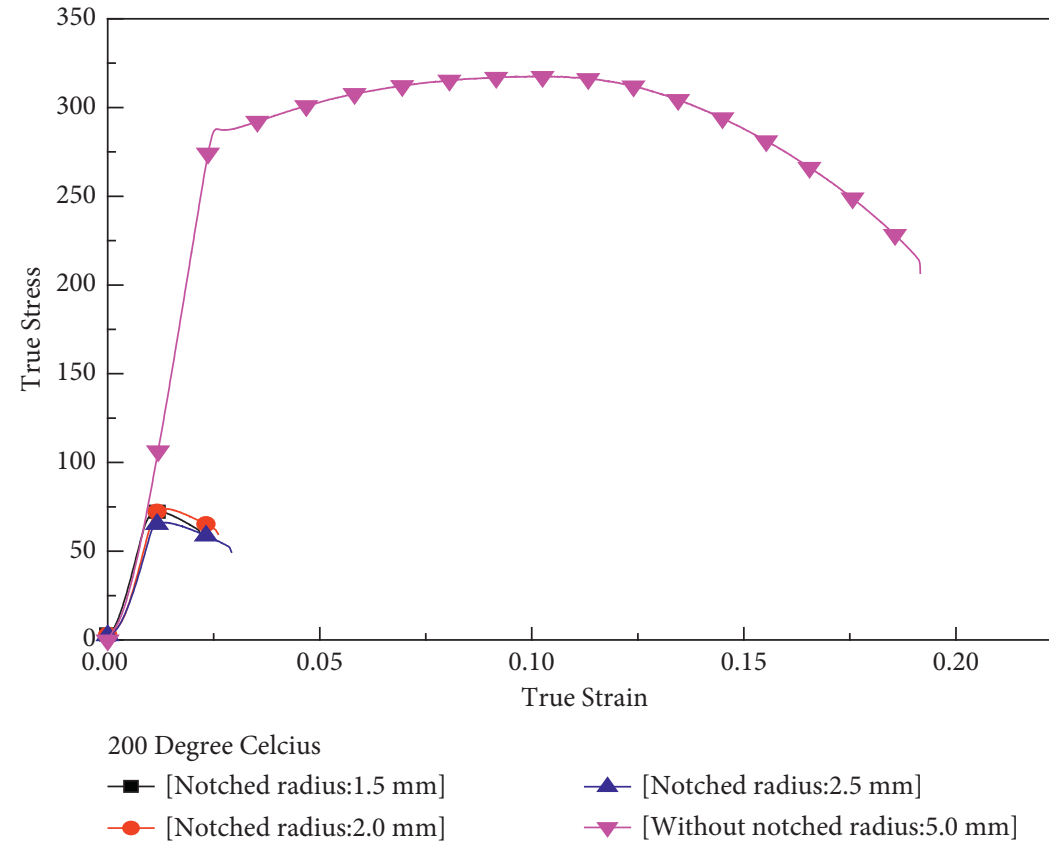

(c)

FIGURE 14: Tensile response of smooth and notched specimen under reference strain-rate $(\dot{\varepsilon})=10^{-3} / \mathrm{s}$. (a) Smooth and notched specimen at $20^{\circ} \mathrm{C}$. (b) Smooth and notched specimen at $100^{\circ} \mathrm{C}$. (c) Smooth and notched specimen at $200^{\circ} \mathrm{C}$.

the average plastic Johnson Cook parameters were evaluated using the graph fitting methods utilizing OriginPro V2017 software, which is shown in Figure 21.

Substituting the values of $A, B$, and $n$ in (24) becomes

$$
\left(A+B\left(\varepsilon^{p}\right)^{n}\right)=\left(318+395\left(\varepsilon^{p}\right)^{0.73707}\right) .
$$

(2) Determination of C. Compression test of the Al6061 alloy shown in Figure 17 whose dimension $\Phi 5 \times 5 \mathrm{~mm}$ carried out at room temperature of $20^{\circ} \mathrm{C}$ under three dynamic strain-rates $(\dot{\varepsilon})$ of $1 \times 10^{3} \mathrm{~s}^{-1}, 2 \times 10^{3} \mathrm{~s}^{-1}$, and $3 \times 10^{3} \mathrm{~s}^{-1}$, respectively. Under this condition, the Johnson-Cook constitutive model (14) becomes

$$
\frac{\sigma}{A}=\left(1+C \log \left(\dot{\varepsilon}^{*}\right)\right)
$$

Then, from the experimental data, plastic strain, true strain, and $\sigma / A$ values were evaluated. The value of $C$ was obtained utilizing the graph fitting methods which were 0.01224 , as shown in Figure 22 . 

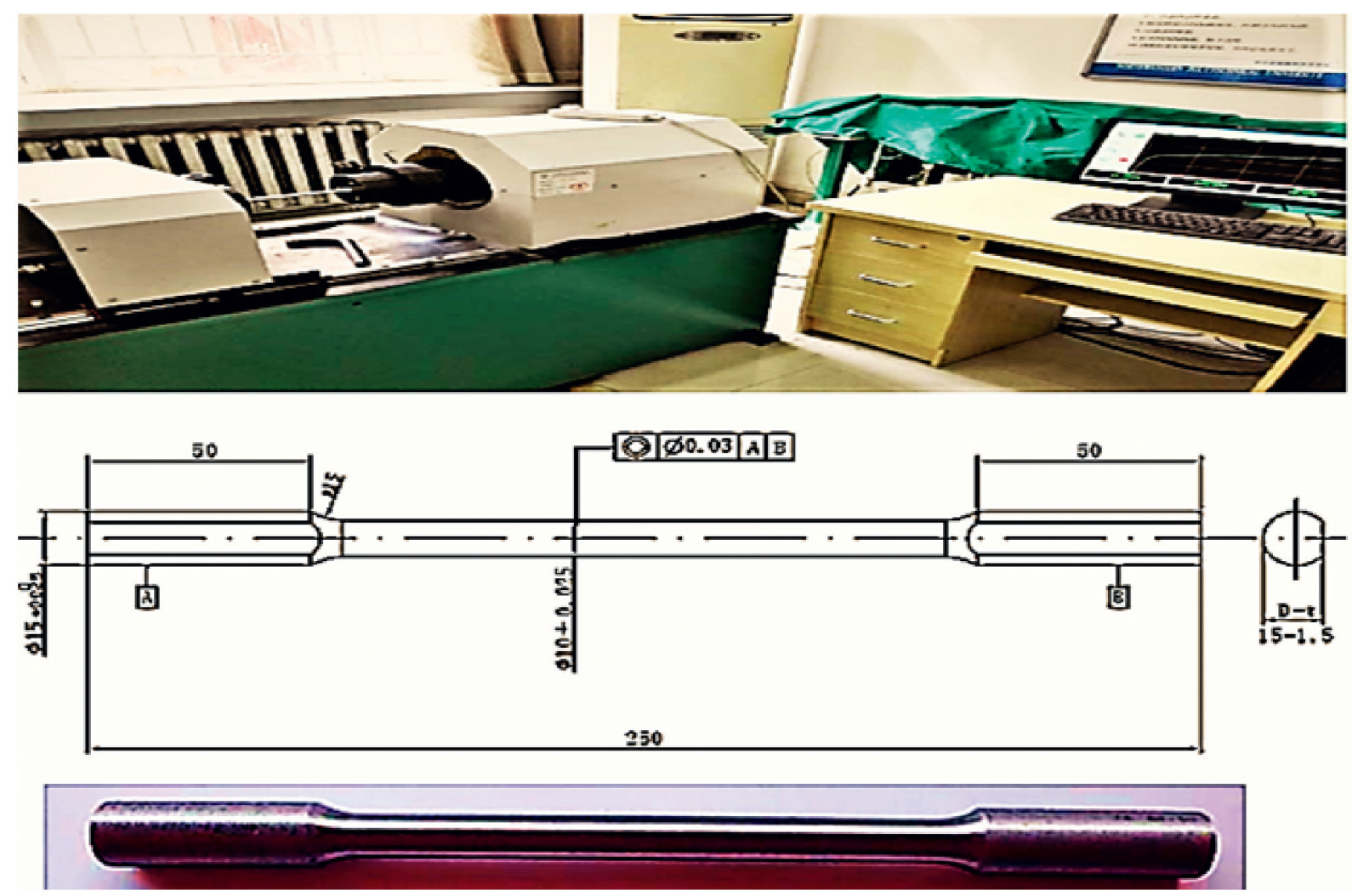

Figure 15: DHW1000 torsion test machine and Dog-bone Al6061 alloy sample.

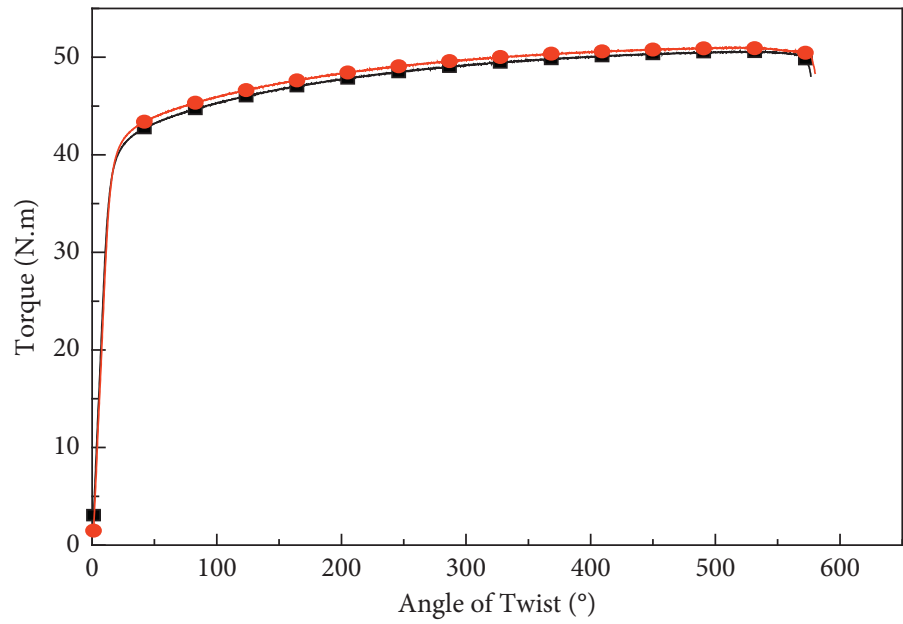

Reference Strain Rate $\left(10^{\wedge}-3\right)$

$\rightarrow-1$ st Test

$\multimap$ 2nd Test

FIGURE 16: Torsional response. Quasi-static torsion test at reference strain-rate $\left(10^{-3} / \mathrm{s}\right)$.

(3) Determination of $m$. Quasi-static tensile tests were performed on smooth specimen shown in Figure12 whose radius was $5.0 \mathrm{~mm}$ at reference strain-rate of $(\dot{\varepsilon})$ of $1 \times 10^{-3} \mathrm{~s}^{-1}$ carried out at three different temperatures such as $20^{\circ} \mathrm{C}, 100^{\circ} \mathrm{C}$, and $200^{\circ} \mathrm{C}$, respectively, and (14) becomes:

$$
\frac{\sigma}{A}=\left(1-T^{* m}\right)
$$

The average true plastic stress and strain were evaluated from the obtained experimental data at three different temperatures. The average value of $m$ of 1.77019 was 

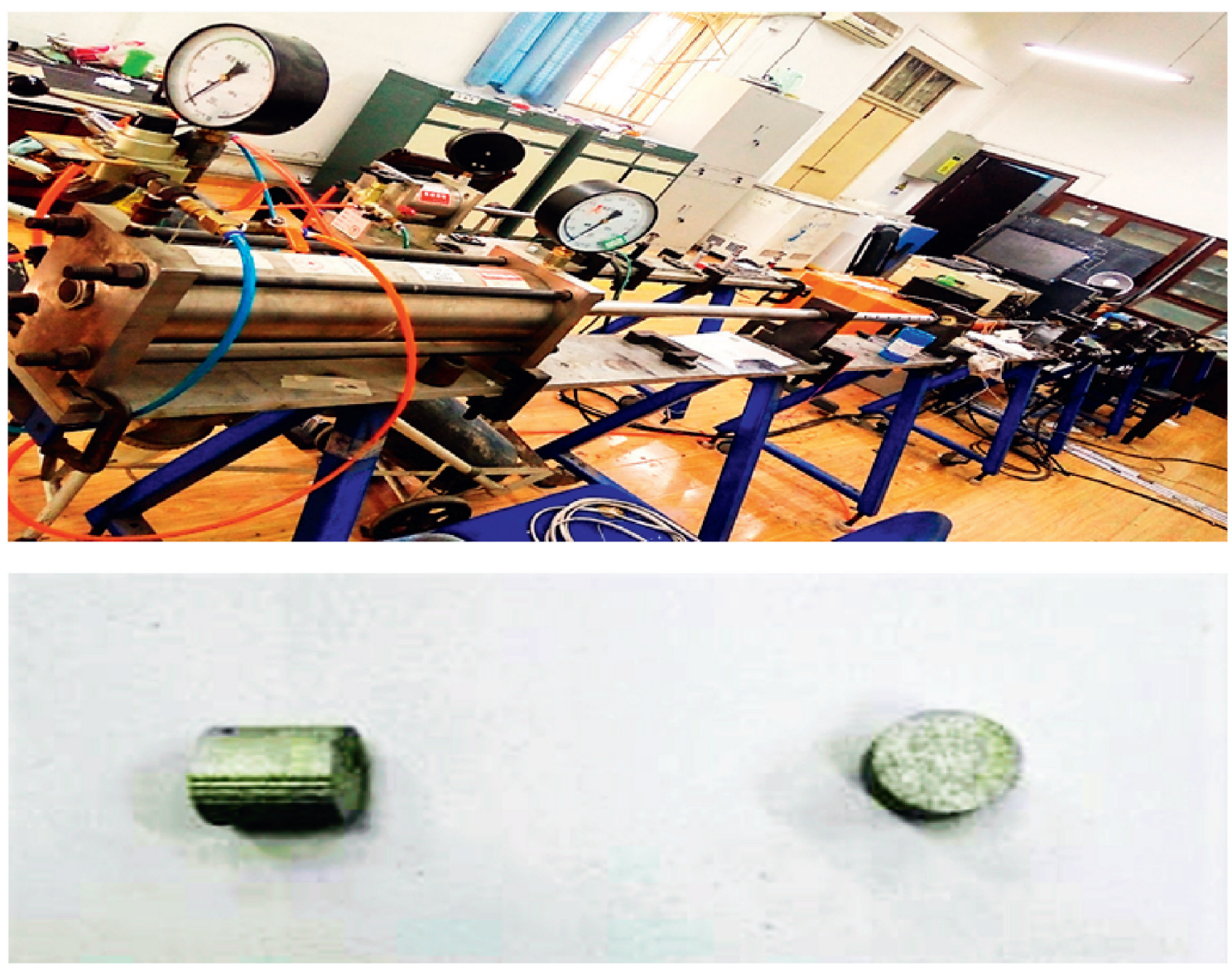

FIGURE 17: SHPB experimental setup and compression sample.

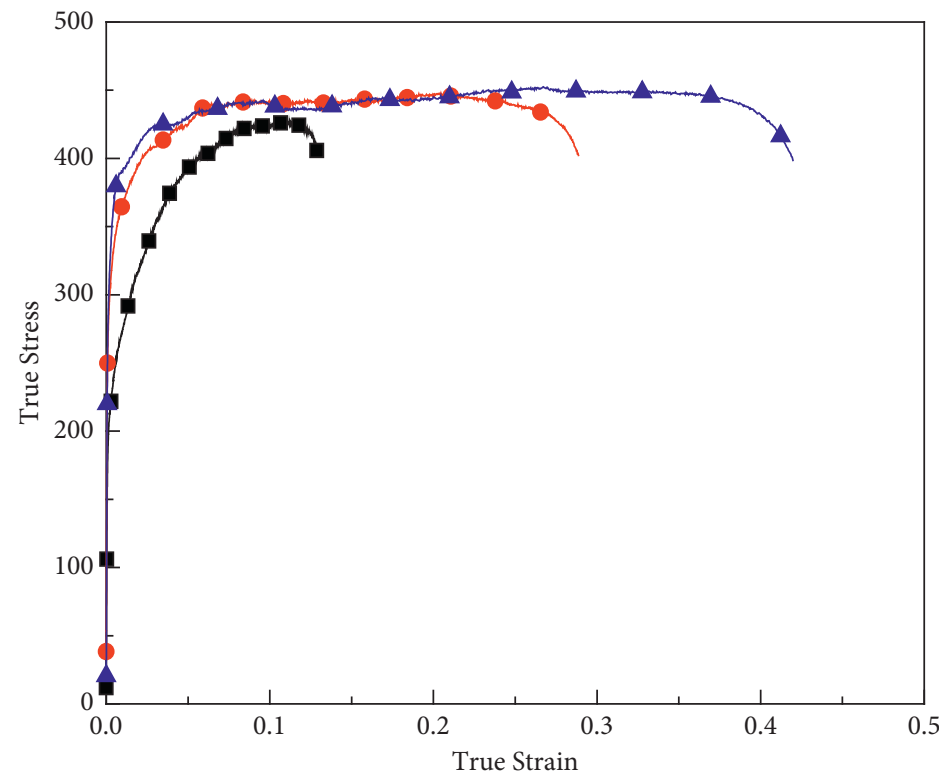

Room Temperature (20 Degree celcius)

- Strain rate: $1000 / \mathrm{s}$

- Strain rate:2000/s

- Strain rate:3000/s

(a)

FIgURE 18: Continued. 


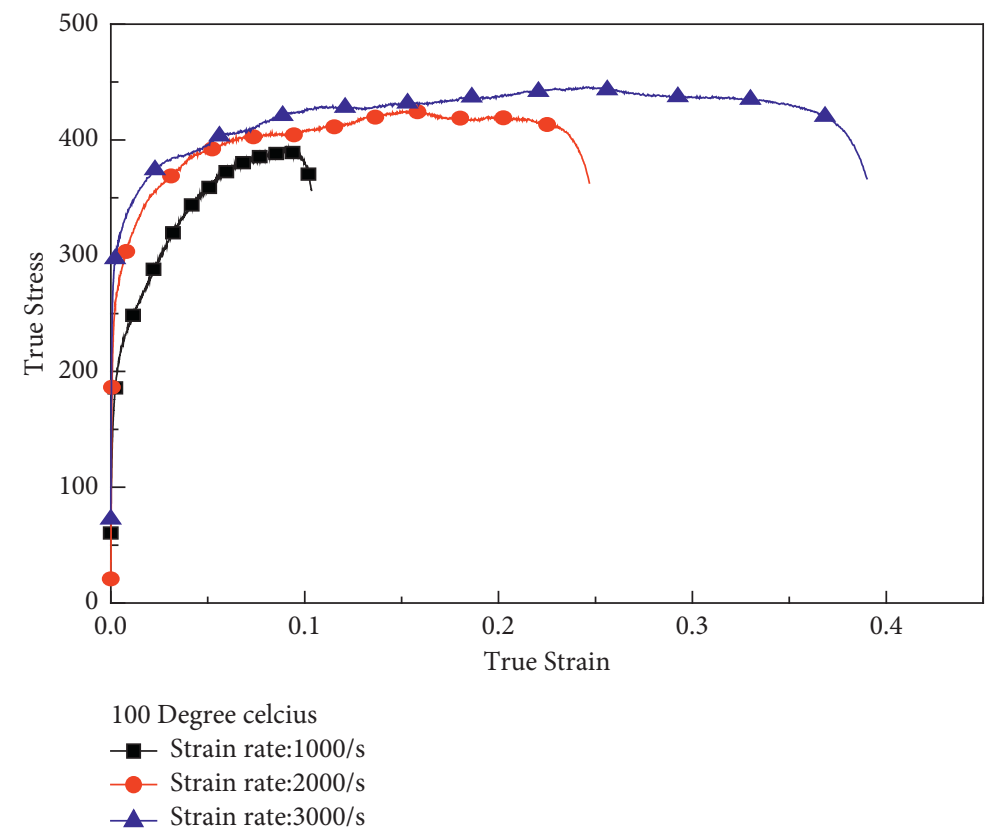

(b)

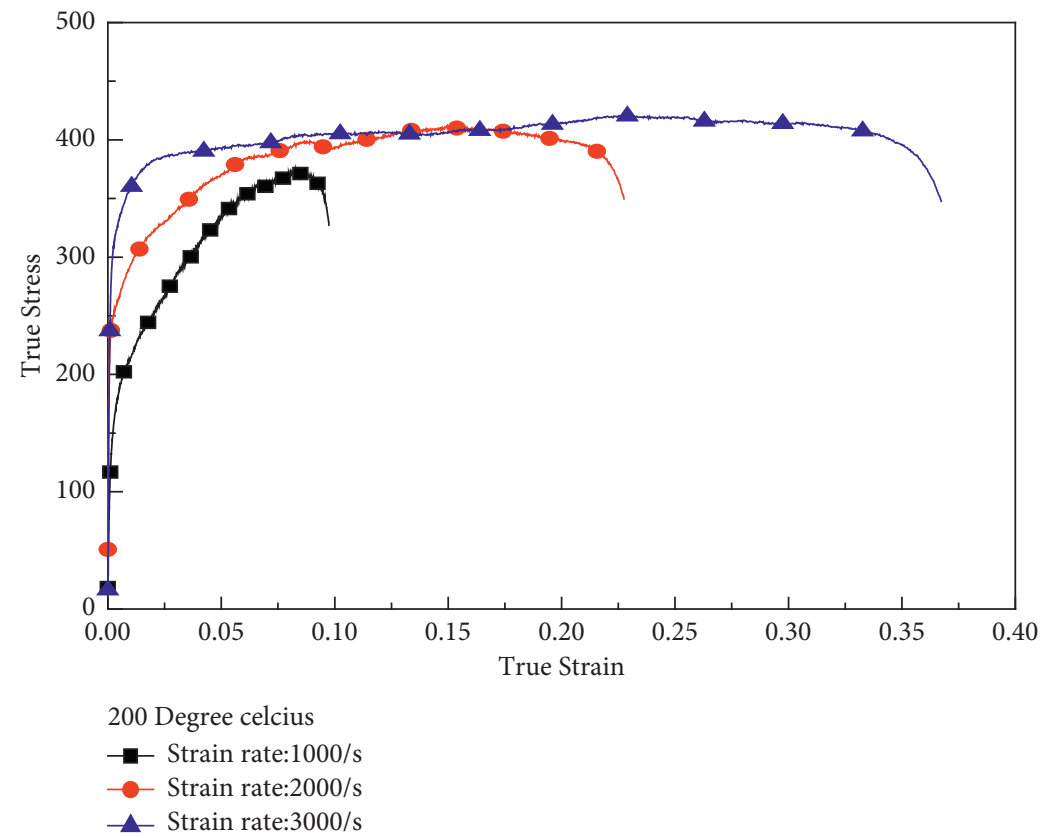

(c)

Figure 18: Compression tests. (a) Compression response at $20^{\circ} \mathrm{C}$ under three strain-rates $(\dot{\varepsilon})$. (b) Compression response at $100^{\circ} \mathrm{C}$ under three strain-rates $(\dot{\varepsilon})$. (c) Compression response at $200^{\circ} \mathrm{C}$ under three strain-rates $(\dot{\varepsilon})$.

obtained utilizing the graph fitting methods, as shown in Figure 23.

The Johnson-Cook plastic constants were evaluated utilizing the graph fitting methods of the Al6061 alloy which is depicted in Table 3.

3.2.2. Johnson-Cook Fracture Parameters. From this experimental test research of Al6061 alloy $\left(R_{0}: 1.5 \mathrm{~mm}, 2.0 \mathrm{~mm}\right.$, and $2.5 \mathrm{~mm}$ ) notched specimens, their corresponding stress triaxiality have been calculated as $0.6248,0.5724$, and 0.5289 , respectively.

(1) Determination of $D_{1}, D_{2}$, and $D_{3}$. Tension tests of the smooth specimen (radius $5.0 \mathrm{~mm}$ ), notched specimen (radii $1.5 \mathrm{~mm}, 2.0 \mathrm{~mm}$, and $2.5 \mathrm{~mm}$ ), and torsion tests of the dog-bone specimen (radius $5.7 \mathrm{~mm}$ and length $14 \mathrm{~mm}$ ) were carried out at room temperature of $20^{\circ} \mathrm{C}$ and reference strain-rate $(\dot{\varepsilon})$ of $1 \times 10^{-3} \mathrm{~s}^{-1}$. Tables $4-8$ of the appendix presents the determination of failure strain and 

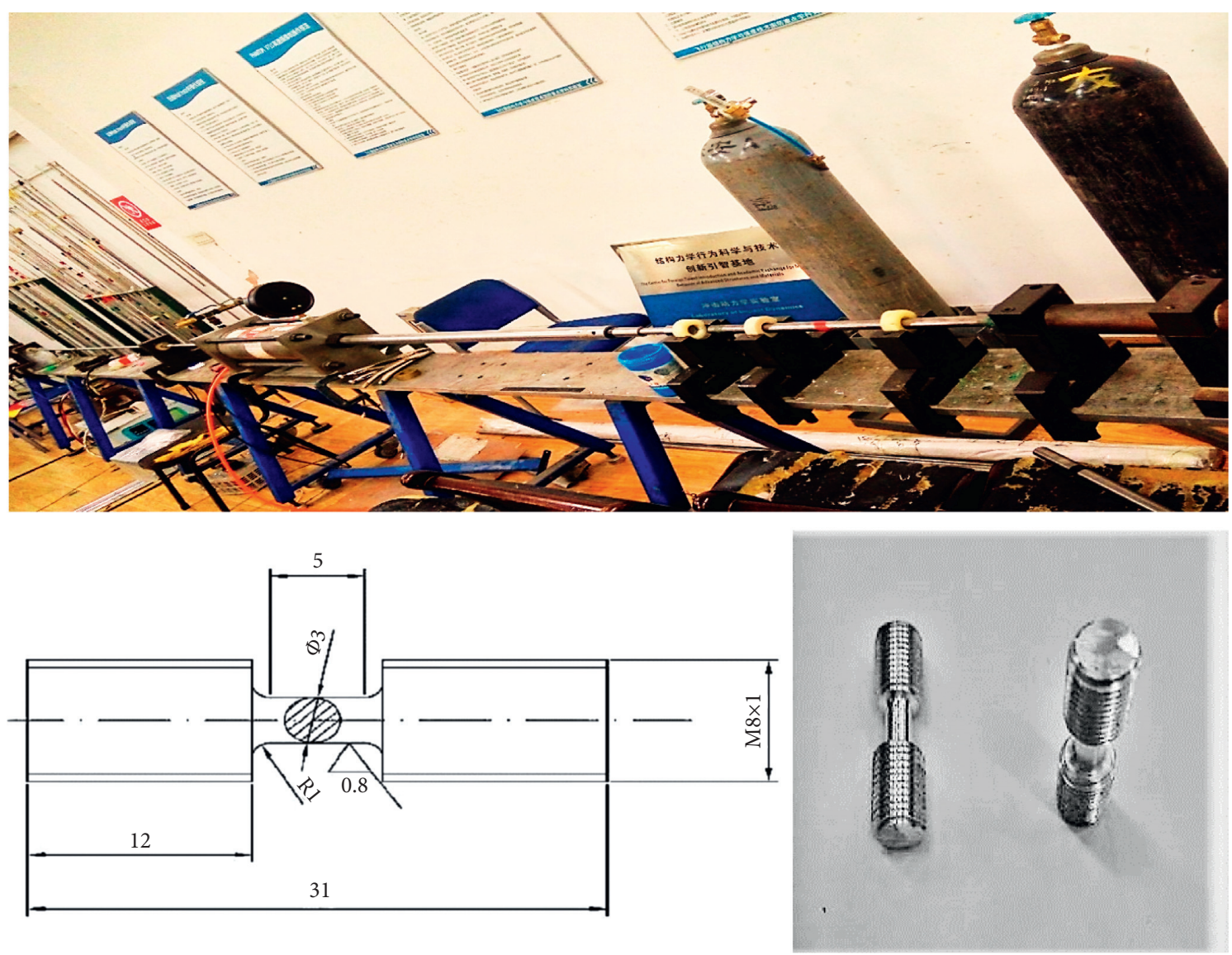

Figure 19: SHTB experimental setup and tension sample.

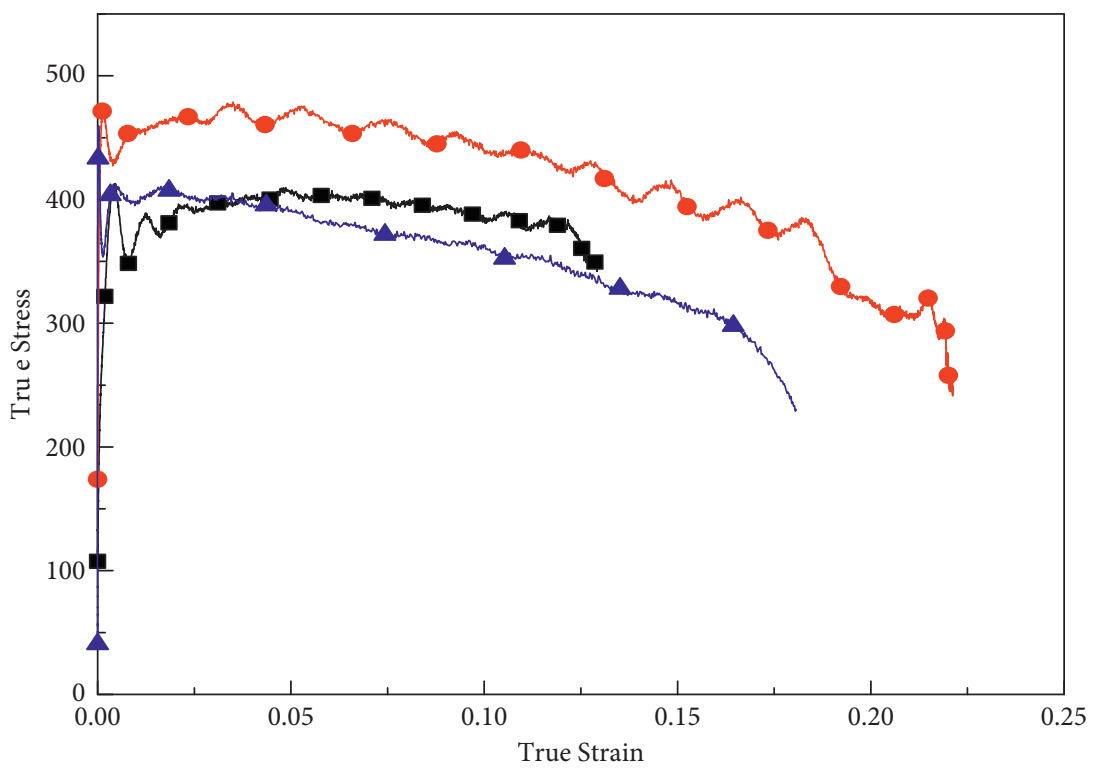

Room Temperature: $\left(20^{\circ} \mathrm{C}\right)$

$\rightarrow$ - Strain rate: $1000 / \mathrm{s}$

- Strain rate:2000/s

_- Strain rate: $3000 / \mathrm{s}$

(a)

Figure 20: Continued. 


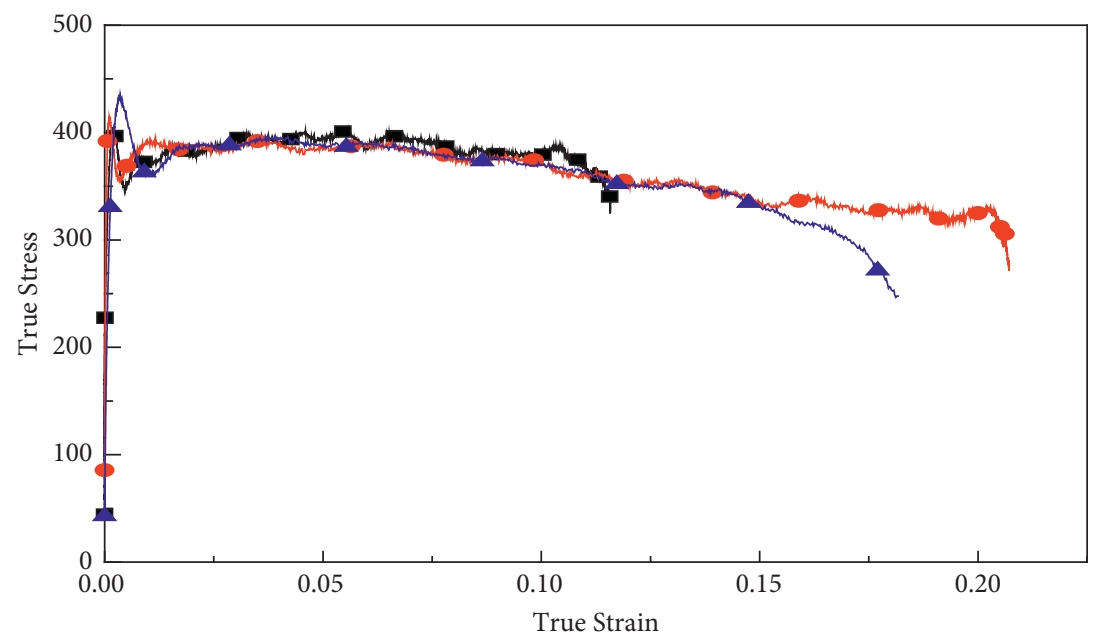

100 Degree celcius

- Strain rate:1000/s

- Strain rate:2000/s

_- Strain rate:3000/s

(b)

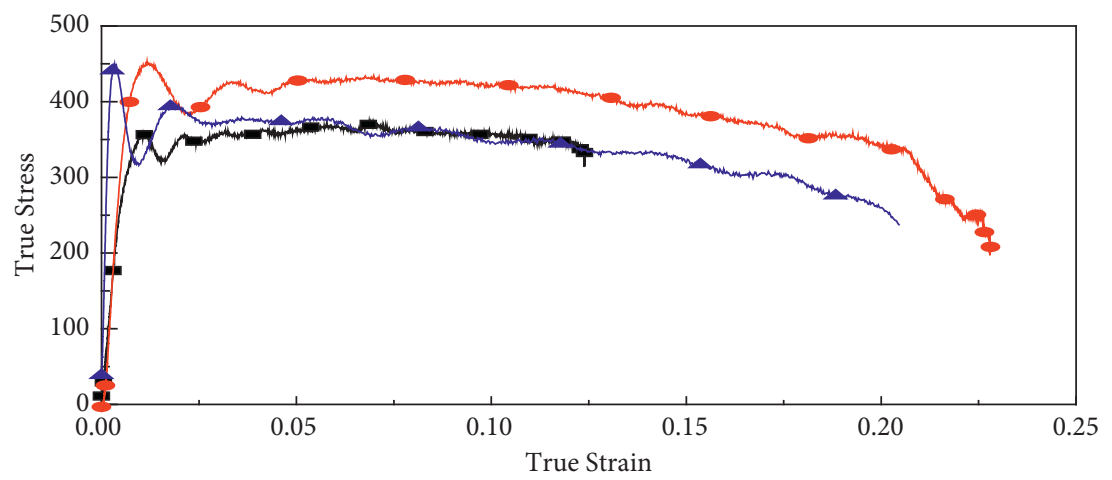

200 Degree celcius

- Strain rate:1000/s

- Strain rate:2000/s

— Strain rate:3000/s

(c)

Figure 20: Tension tests. (a) Tension response at $20^{\circ} \mathrm{C}$ under three strain-rates $(\dot{\varepsilon})$. (b) Tension response at $100^{\circ} \mathrm{C}$ under three strain-rates $(\dot{\varepsilon})$. (c) Tension response at $200^{\circ} \mathrm{C}$ under three strain-rates $(\dot{\varepsilon})$.

TABLE 2: Obtained values of $A, B$, and $n$.

\begin{tabular}{lcr}
\hline SN & Johnson-Cook strength parameter & Average obtained fitted values \\
\hline 1 & $A$ & 318 \\
2 & $B$ & 395 \\
3 & $n$ & 0.73707 \\
\hline
\end{tabular}

stress triaxiality under the reference strain-rate. Under this state, we may write (17) as

$$
\varepsilon^{f}=\left(D_{1}+D_{2} \exp D_{3} \sigma^{*}\right) \text {. }
$$

Then, the fracture strain $\left(\varepsilon^{f}\right)$ and triaxiality state of stress $\left(\sigma^{*}\right)$ were evaluated using the high-speed camera from the experimental tension tests results of the smooth, notched specimen and torsion tests using dog-bone specimen under reference strain-rate represented by substitute (28). Average fitting values of Johnson-Cook constants of $D_{1}, D_{2}$, and $D_{3}$ are 0.08196, 2.27659, and F02D1.81322, respectively, as shown in Figure 24.

$$
\varepsilon^{f}=\left(0.08196+2.27659 * \exp \left(-1.81322 *\left(-\frac{1}{3}\right)\right) .\right.
$$

(2) Determination of D4. The smooth specimen shown in Figure 12 carried out dynamic tensile tests under three different strain-rates $(\dot{\varepsilon})$ of $1 \times 10^{-3} \mathrm{~s}^{-1}, 2 \times 10^{-3} \mathrm{~s}^{-1}$, and 


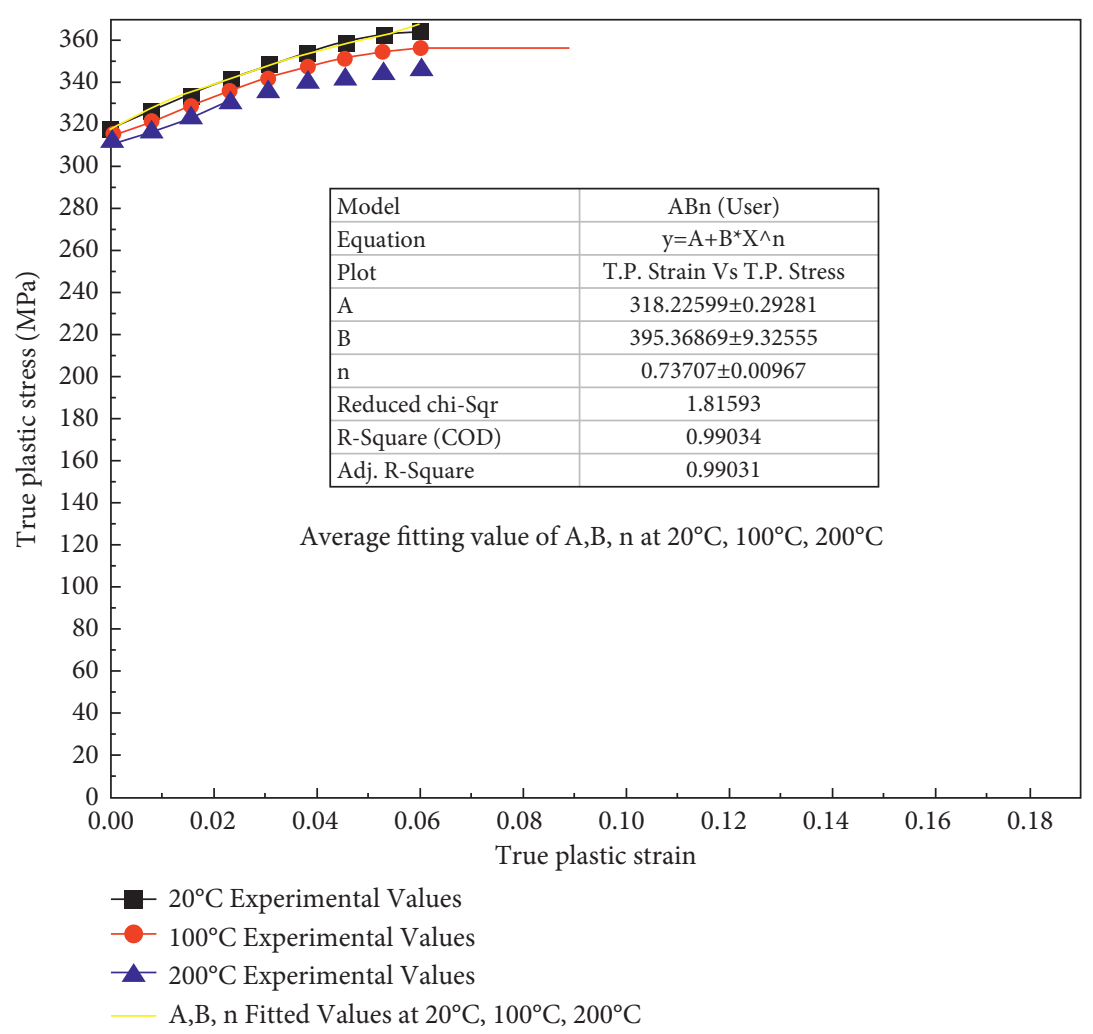

FIgURE 21: Average fitting values of $A, B$, and $n$.

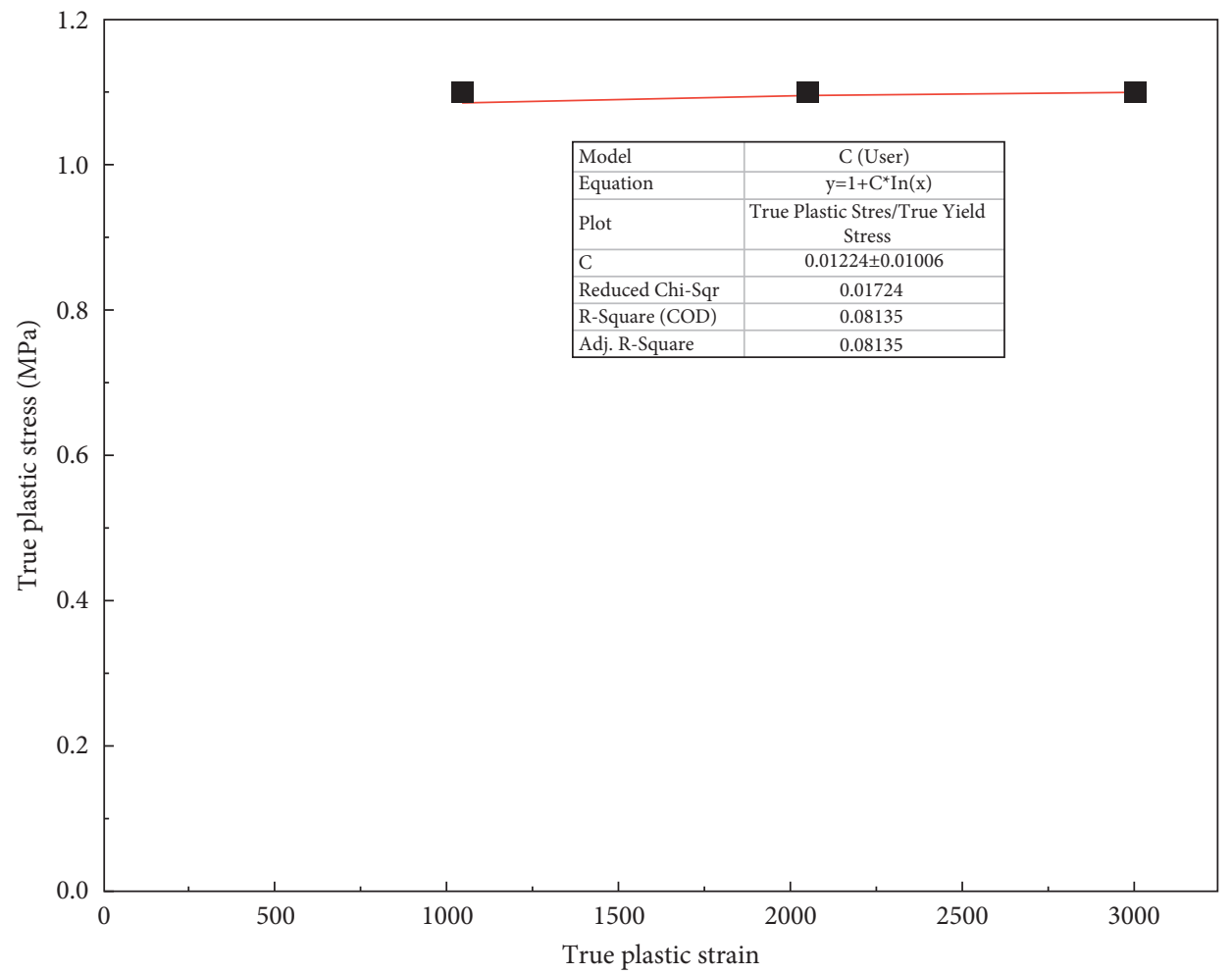

Experimental data at room temperature Average Fitted value of $\mathrm{C}$

Figure 22: Average fitting value of $C$. 


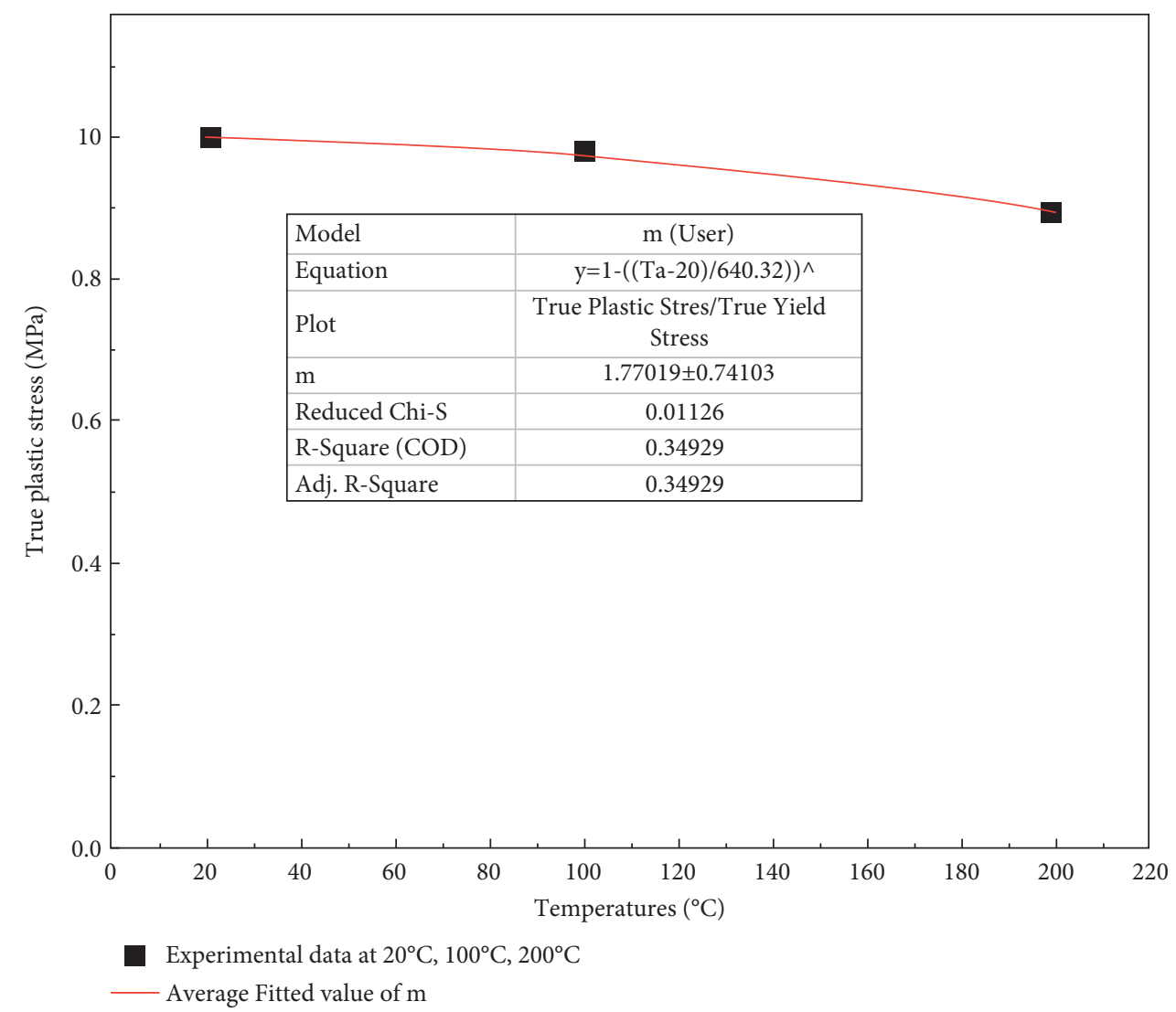

Figure 23: Average fitting value of $m$.

TABLE 3: Johnson-Cook plastic constants of Al6061 alloy.

\begin{tabular}{lccccc}
\hline Constants & $A$ & $B$ & $n$ & $C$ & $m$ \\
\hline Al6061 alloy & 318.22599 & 395.36869 & 0.73707 & 0.01224 & 1.77019 \\
\hline
\end{tabular}

TABLE 4: Notched radii $=1.5 \mathrm{~mm}$ at $20^{\circ} \mathrm{C}$ under reference strain-rate $\dot{\varepsilon}: 1 \times 10^{-3} / \mathrm{s}$.

\begin{tabular}{lcc}
\hline SN & Failure strain $\left(\varepsilon^{f}=\left(2 \log \left(d / d_{f}\right)\right)\right)$ & Stress triaxiality $\left(\sigma^{*}=1 / 3+\log (1+a / 2 R)\right)$ \\
\hline 1. & $\varepsilon^{f}=2 \log (54 / 40)=2 \log (1.325)$ & $\sigma^{*}=1 / 3+\log (1+(2.18 / 2 \times 1.5))$ \\
2. & $\varepsilon^{f}=2 \log (53 / 42)=2 \log (1.2619047)$ & $\sigma^{*}=1 / 3+\log (1+(2.26 / 2 \times 1.5))$ \\
3. & $\varepsilon^{f}=2 \log (53 / 41)=2 \log (1.292682926)$ & $\sigma^{*}=1 / 3+\log (1+(2.22 / 2 \times 1.5))$ \\
\hline
\end{tabular}

TABle 5: Notched radii $=2.0 \mathrm{~mm}$ at $20^{\circ} \mathrm{C}$ under reference strain-rate $\dot{\varepsilon}: 1 \times 10^{-3} / \mathbf{s}$.

\begin{tabular}{lcc}
\hline SN & Failure strain $\left(\varepsilon^{f}=\left(2 \log \left(d / d_{f}\right)\right)\right)$ & Stress triaxiality $\left(\sigma^{*}=1 / 3+\log (1+a / 2 R)\right)$ \\
\hline 1. & $\varepsilon^{f}=2 \log (54 / 36)=2 \log (1.5)$ & $\sigma^{*}=1 / 3+\log (1+(2.22 / 2 \times 2.0))=1 / 3+\log (1.555)$ \\
2. & $\varepsilon^{f}=2 \log (53 / 41)=2 \log (1.2126829)$ & $\sigma^{*}=1 / 3+\log (1+(2.22 / 2 \times 2.0))=1 / 3+\log (1.555)$ \\
3. & $\varepsilon^{f}=2 \log (53 / 42)=2 \log (1.28571426)$ & $\sigma^{*}=1 / 3+\log (1+(2.22 / 2 \times 2.0))=1 / 3+\log (1.555)$ \\
\hline
\end{tabular}

TABle 6: Notched radii $=2.5 \mathrm{~mm}$ at $20^{\circ} \mathrm{C}$ under reference strain-rate $\dot{\varepsilon}: 1 \times 10^{-3} / \mathbf{s}$.

\begin{tabular}{lcc}
\hline SN & Failure strain $\left(\varepsilon^{f}=\left(2 \log \left(d / d_{f}\right)\right)\right)$ & Stress triaxiality $\left(\sigma^{*}=1 / 3+\log (1+a / 2 R)\right)$ \\
\hline 1. & $\varepsilon^{f}=2 \log (53 / 40)=2 \log (1.325)$ & $\sigma^{*}=1 / 3+\log (1+(2.22 / 2 \times 2.5))=1 / 3+\log (1.444)$ \\
2. & $\varepsilon^{f}=2 \log (53 / 41)=2 \log (1.29268293)$ & $\sigma^{*}=1 / 3+\log (1+(2.22 / 2 \times 2.5))=1 / 3+\log (1.444)$ \\
3. & $\varepsilon^{f}=2 \log (53 / 42)=2 \log (1.26190476)$ & $\sigma^{*}=1 / 3+\log (1+(2.22 / 2 \times 2.5))=1 / 3+\log (1.444)$ \\
\hline
\end{tabular}


TABle 7: Radii $=5.0 \mathrm{~mm}$ at $20^{\circ} \mathrm{C}$ under reference strain-rate $\dot{\varepsilon}: 1 \times 10^{-3} / \mathrm{s}$.

\begin{tabular}{lcc}
\hline SN & Failure strain $\left(\varepsilon^{f}=\left(2 \log \left(d / d_{f}\right)\right)\right)$ & Stress triaxiality $\left(\sigma^{*}=1 / 3+\log (1+a / 2 R)\right)$ \\
\hline 1. & $\varepsilon^{f}=2 \log (119 / 81)=2 \log (1.4691358)$ & $\sigma^{*}=1 / 3+\log (1+(5.0 / 2 \times 5.0))=1 / 3+\log (1.5)$ \\
2. & $\varepsilon^{f}=2 \log (121 / 93)=2 \log (1.30107527)$ & $\sigma^{*}=1 / 3+\log (1+(5.0 / 2 \times 5.0))=1 / 3+\log (1.5)$ \\
3. & $\varepsilon^{f}=2 \log (119 / 80)=2 \log (1.4875)$ & $\sigma^{*}=1 / 3+\log (1+(5.0 / 2 \times 5.0))=1 / 3+\log (1.5)$ \\
\hline
\end{tabular}

TAble 8: Radii $=5.0 \mathrm{~mm}$ at $20^{\circ} \mathrm{C}$ under reference strain-rate $\dot{\varepsilon}: 1 \times 10^{-3} / \mathrm{s}$.

\begin{tabular}{lcc}
\hline SN & Failure strain $\left(\varepsilon^{f}=r_{f} / \sqrt{3}\right)$ & Stress triaxiality $\left(\sigma^{*}=0\right)$ \\
\hline 1. & $\varepsilon^{f}=(5.7 * 610.5312271 * 3.14) /(1.7320508 * 180 * 13.74)$ & $\sigma^{*}=0$ \\
2. & $\varepsilon^{f}=(5.7 * 804.486958440488 * 3.14) /(1.7320508 * 180 * 13.76)$ & $\sigma^{*}=0$ \\
3. & $\varepsilon^{f}=(5.7 * 593.179758867875 * 3.14) /(1.7320508 * 180 * 13.88)$ & $\sigma^{*}=0$ \\
\hline
\end{tabular}

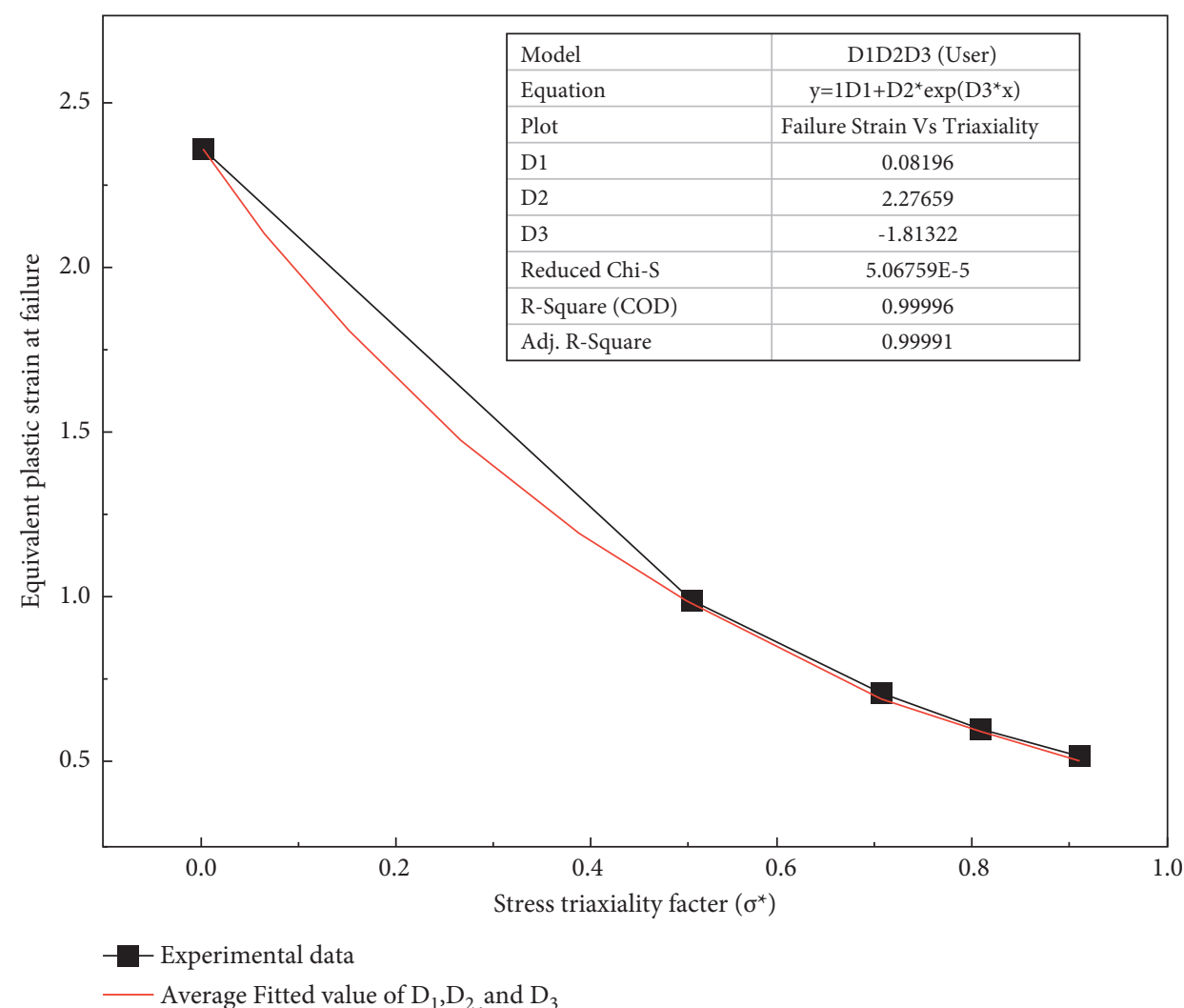

FIgURE 24: Average fitting values of $D_{1}, D_{2}$, and $D_{3}$.

$3 \times 10^{-3} \mathrm{~s}^{-1}$ at room temperature $\left(20^{\circ} \mathrm{C}\right)$. The fracture process was recorded by a high-speed camera and the calculation of average failure strain under three strain-rates were calculated as $0.8497,0.6767$, and 0.9458 , respectively, as shown in
Figure 25. Table 9 of the appendix presents the calculation of average failure strain under strain-rates of 1000/s, 2000/s, and 3000/s, respectively. The average graph fitting value of $D_{4}$ is -0.07239 then equation (21) can be written as follows:

$$
\varepsilon^{f}=\left(0.08196+2.27659 * \exp \left(-1.81322 *\left(-\frac{1}{3}\right)\right)\left(1+(-0.07239) \log \varepsilon^{*}\right) .\right.
$$

(3) Determination of D5. The smooth specimen shown in Figure 12 performed tensile tests under reference strain rate $(\dot{\varepsilon}) 1 \times 10-3 \mathrm{~s}-1$ at room temperature $\left(20^{\circ} \mathrm{C}\right)$ to elevated temperatures $100^{\circ} \mathrm{C}$ and $200^{\circ} \mathrm{C}$, respectively. The fracture process was recorded by a high-speed camera. The average graph fitting value of D5 is -0.00626 which is 


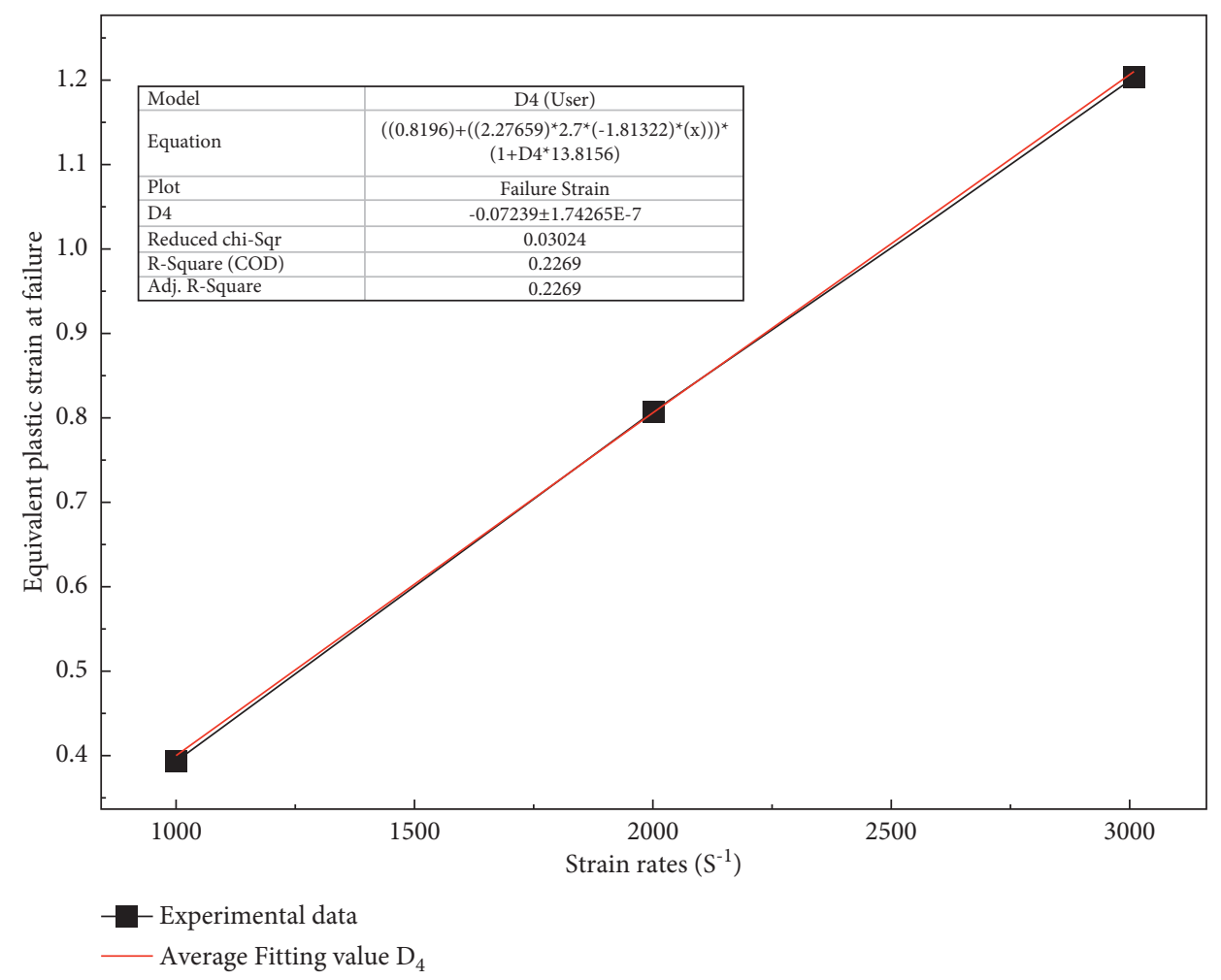

FIgURE 25: Average fitting values of $D_{4}$.

TABLE 9: Radius $=3.0 \mathrm{~mm}$ and length $=5.0 \mathrm{~mm}$ at $20^{\circ} \mathrm{C}$ under different strain-rate $\left(\dot{\varepsilon}: 1 \times 10^{3} / \mathrm{s}, 2 \times 10^{3} / \mathbf{s}, 3 \times 10^{3} / \mathbf{s}\right)$, respectively.

\begin{tabular}{|c|c|c|c|}
\hline SN & Failure strain $\left(\varepsilon^{f}=\left(2 \log \left(d / d_{f}\right)\right)\right)$ & & Strain-rates $(\dot{\varepsilon})$ \\
\hline 1. & $\begin{aligned} \mathcal{E}^{f} & =2 \times \log (105 / 68) \\
\mathcal{E}^{f} & =2 \times \log (104 / 68)\end{aligned}$ & Avg. $\mathcal{E}^{f}=0.849766388$ & $1000 / \mathrm{s}$ \\
\hline 2. & $\begin{array}{l}\varepsilon^{f}=2 \times \log (105 / 75) \\
\varepsilon^{f}=2 \times \log (104 / 75)\end{array}$ & Avg. $\mathcal{E}^{f}=0.676798043$ & $2000 / \mathrm{s}$ \\
\hline 3. & $\begin{array}{l}\mathcal{E}^{f}=2 \times \log (104 / 64) \\
\varepsilon^{f}=2 \times \log (103 / 65)\end{array}$ & Avg. $\mathcal{E}^{f}=0.945849534$ & $3000 / \mathrm{s}$ \\
\hline
\end{tabular}

shown in Figure 26. Table 10 of the appendix presents the calculations of failure strains at three different temperatures. The Johnson-Cook fracture (20) can be written as

$$
\mathcal{E}^{f}=\left(0.08196+2.27659 * \exp \left(-1.81322 *\left(-\frac{1}{3}\right)\right)\left(1+(-0.07239) \log \varepsilon^{*}\right)+(1-0.00626) .\right.
$$

The Johnson-Cook fracture constants were evaluated using the graph fitting methods of the Al6061 alloy, which are depicted in Table 11.

3.3. Numerical Simulations. The finite element software ABAQUS/CAE was utilized to model the bullet impact and the corresponding numerical simulations. The cylindrical bullet was deployed to impact over a square plate of Al6061 alloy. Several impact simulations were carried out to determine the critical perforation velocity when the bullet projected normal to the square flat specimen. The
Johnson-Cook plastic and fracture constants were evaluated using OriginPro-V2017.

3.3.1. Modeling of Bullet and Al6061 Alloy Plate. The bluntnosed cylindrical bullet was assigned all the material properties of stainless steel. The evaluated Johnson-Cook constant parameters were assigned for the Al6061 alloy specimen. The 50-gram bullet's length $50 \mathrm{~mm}$ and diameter $12 \mathrm{~mm}$ projected normal to the center of the specimen $\left(205 \times 205 \times 2 \mathrm{~mm}^{3}\right)$. The design, modeling, and simulation were carried out using ABAQUS/CAE software. Several 


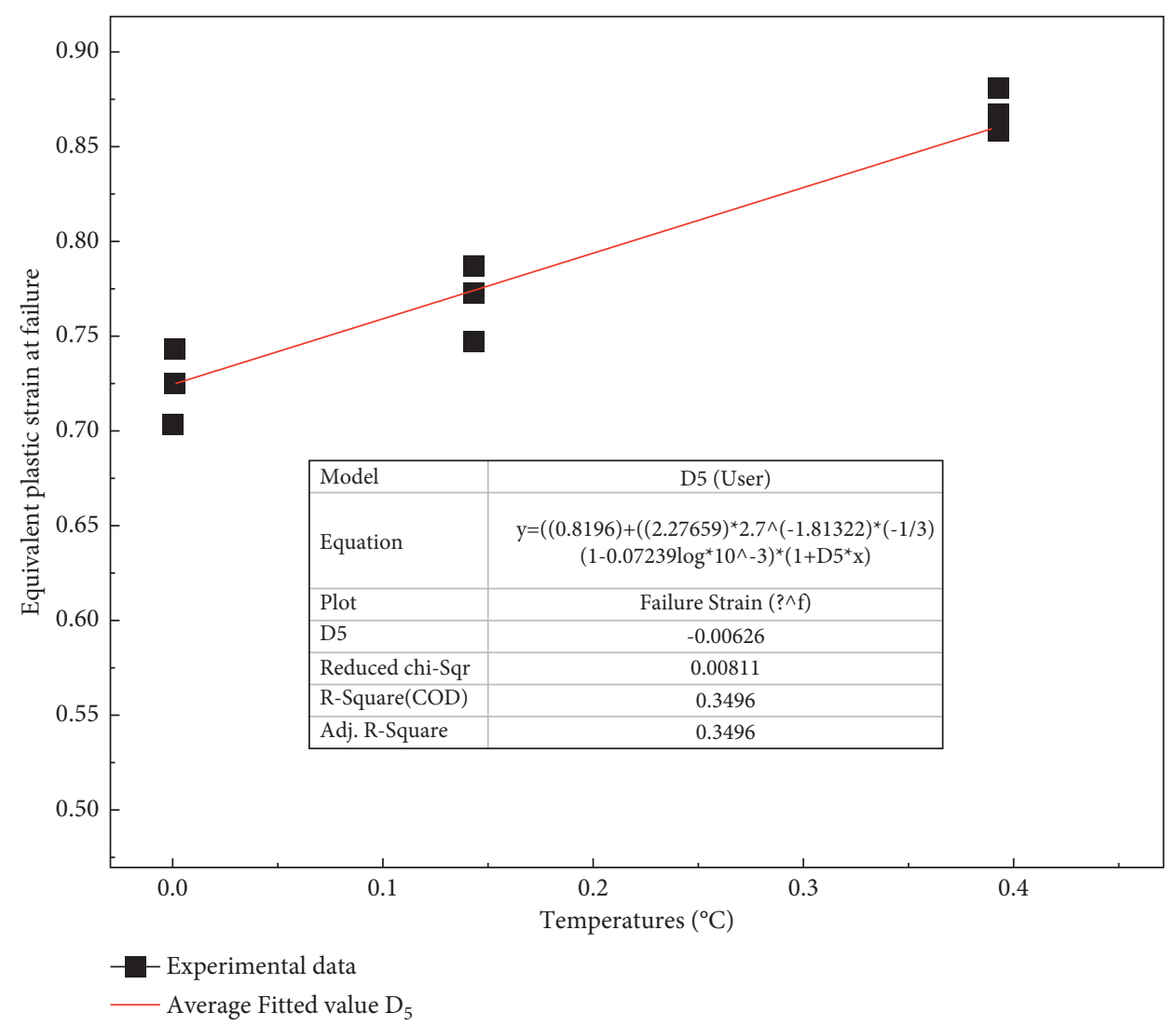

Figure 26: Average fitting value of $D_{5}$.

TABLE 10: Failure strain-Temperatures.

\begin{tabular}{|c|c|c|}
\hline SN & Failure strain $\left(\varepsilon^{f}\right)$ & Temperatures \\
\hline \multirow{3}{*}{1.} & 0.794193717 & \multirow{4}{*}{$20^{\circ} \mathrm{C}$} \\
\hline & 0.526382105 & \\
\hline & 0.794139717 & \\
\hline \multirow{3}{*}{2.} & 0.713349888 & \\
\hline & 0.867729165 & \multirow[t]{2}{*}{$100^{\circ} \mathrm{C}$} \\
\hline & 0.747932882 & \\
\hline \multirow{3}{*}{3.} & 0.892574205 & \multirow{3}{*}{$200^{\circ} \mathrm{C}$} \\
\hline & 0.867729165 & \\
\hline & 0.818946259 & \\
\hline
\end{tabular}

TABLE 11: Johnson-Cook fracture constant of Al 6061 alloy.

\begin{tabular}{lccccc}
\hline Constants & $D_{1}$ & $D_{2}$ & $D_{3}$ & $D_{4}$ & $D_{5}$ \\
\hline Al6061 & 0.08196 & 2.27659 & -1.81322 & -0.07239 & -0.00626 \\
\hline
\end{tabular}

impacts have been carried out to determine the critical perforation velocity. The sensitivity of element size was carried out and appropriate sizes were assigned in the geometry, which is presented in Figure 27. The boundary condition was set to the outer facing four edges of the plate, wherein $A, B$, and $C$ of the flat plate and their element size were assigned as $3 \times 2,2 \times 2$, and $3 \times 3$, respectively. The total number of nodes and elements of the messed specimen were 36975 \& 28896, while the central impact regions were 19945 \& 15376. The critical perforation velocity was found to be
$70 \mathrm{~ms}^{-1}$ when a rigid steel bullet was fired normally to the center of the flat plate.

\section{Results and Observations}

4.1. Numerical Simulation Results. The finite element software ABAQUS/CAE was utilized to model and the numerical simulations were carried out for bullet impact. The cylindrical bullet was deployed to impact normal to the center of a square plate Al6061 alloy. Several bullet impact simulations were carried out to find the critical perforation velocity of the specimen. The Johnson-Cook's plastic and fracture constants were evaluated and justified material properties before running the numerical simulation. The critical perforation velocity was found to be $70 \mathrm{~ms}^{-1}$ and impact scenarios are shown in Figure 28. 


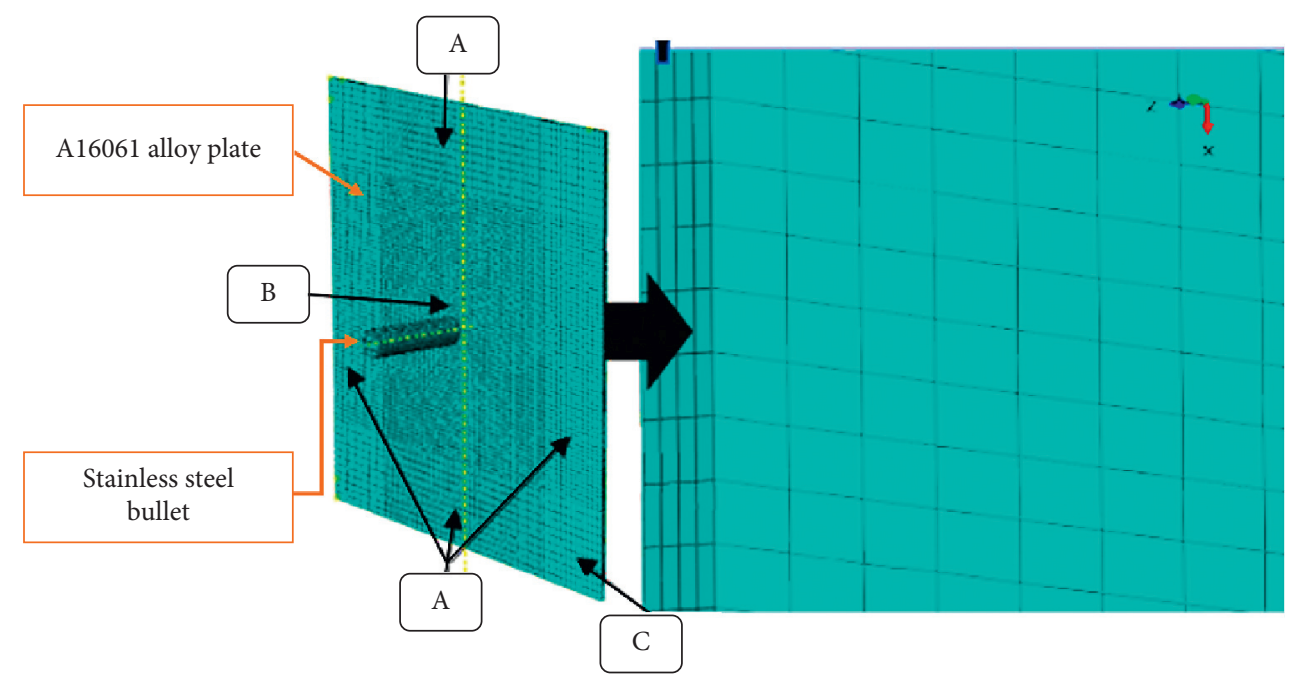

FIgURE 27: Al6061 flat plate with a stainless steel bullet.

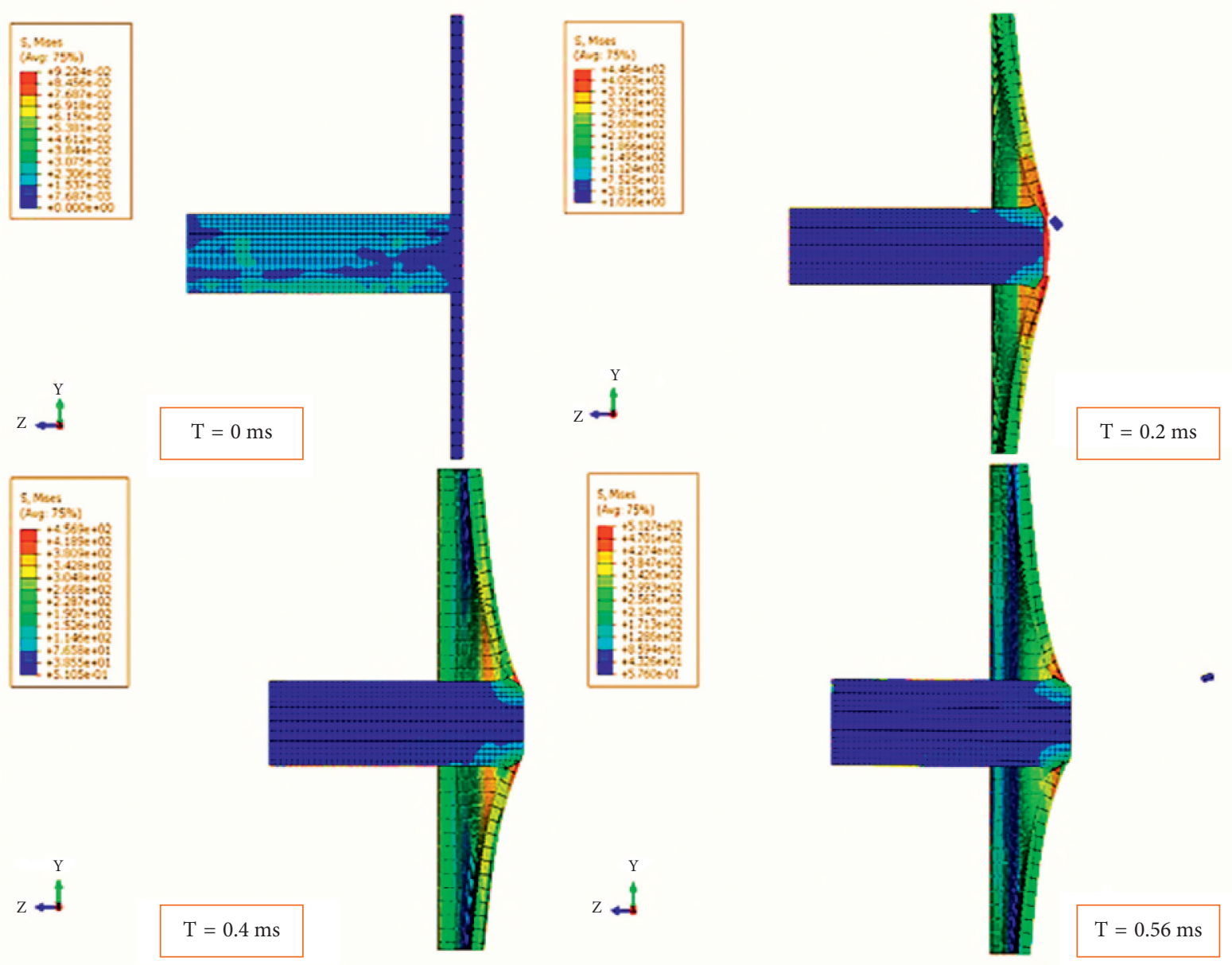

FIGURE 28: Critical perforation velocity.

Two unit-cells with element numbers 9288 and 1172 at a distance of $40 \mathrm{~mm}$ from the central element with number 9264 facing the X- and Y-axis, respectively, are chosen for numerical simulation. The strain gauges were fixed at three places, $40 \mathrm{~mm}$ far from the impact center facing the $\mathrm{X}$ - and Y-axis, respectively, during the experimental tests to compare impact behavior numerically. The true strain was much higher when a bullet was fired with $70 \mathrm{~ms}^{-1}$ and the strain 

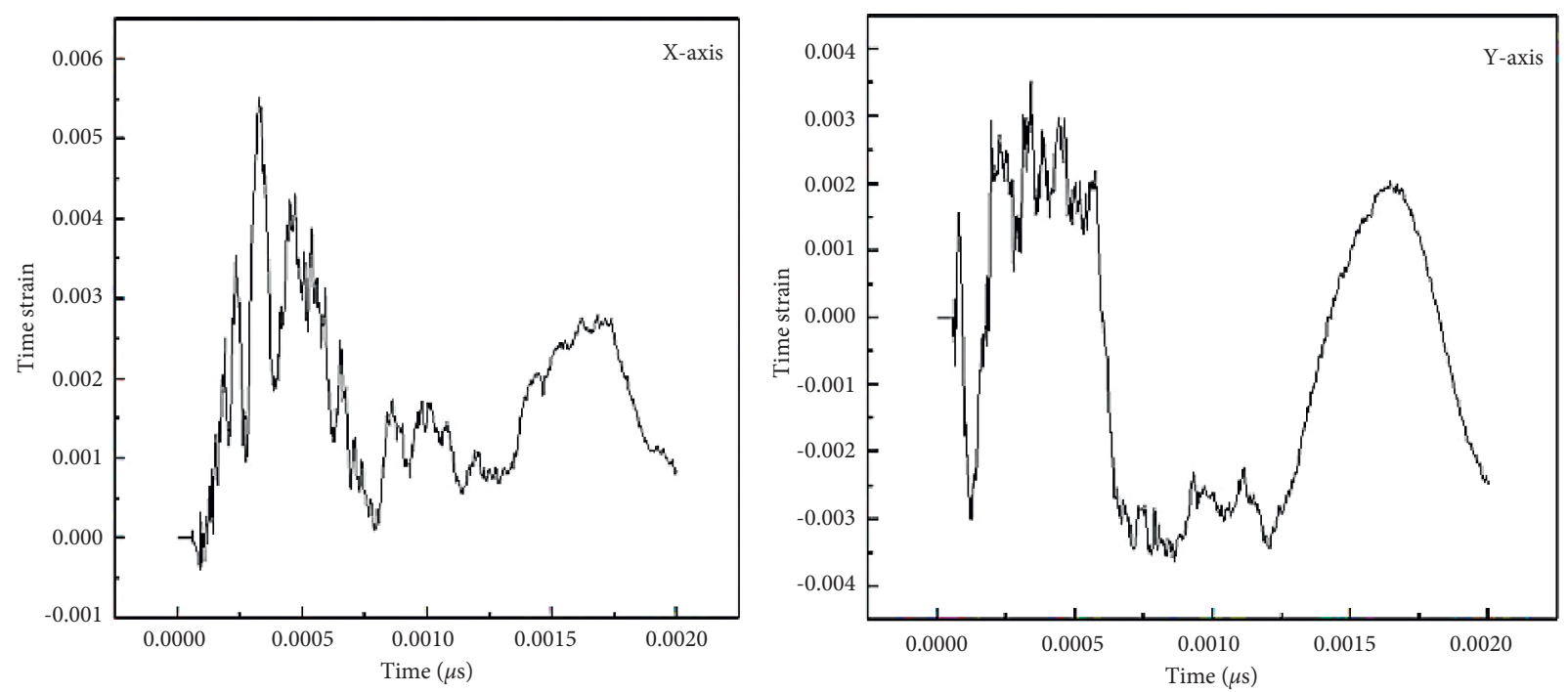

FIgURE 29: Strain produced at $70 \mathrm{~ms}^{-1}$.
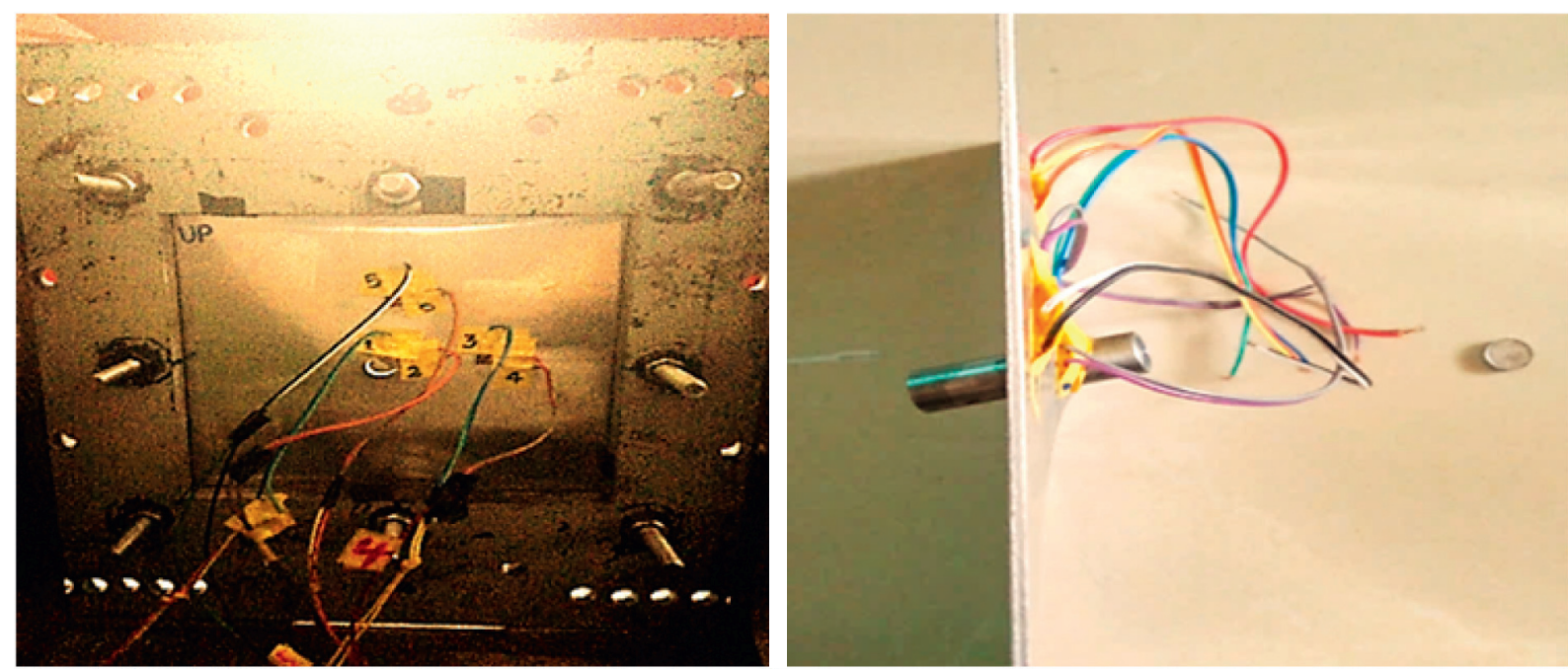

FIgURE 30: Critical perforation velocity.

produced was 0.00525 and 0.00325 , respectively, on $X$-axis and $Y$-axis during the $2 \mu$ s time of impact, which is shown in Figure 29.

4.2. Experimental Results. The Al60601 alloy of the square flat plate specimen $\left(205 \times 205 \times 2 \mathrm{~mm}^{3}\right)$ was prepared. The cylindrical blunt-nosed stainless steel bullet weighing $0.05 \mathrm{~kg}$ was fired normally to the center of the specimen to predict the critical perforation velocity of the plate under a highvelocity impact. Three strain gauges at three different locations on the specimen were fixed, one at the exact center and two lateral sides at a distance of $40 \mathrm{~mm}$ far from the center facing $X$ - and $Y$-axis, respectively, with the help of glue. The nomenclature was done such that $(4,3),(0,5)$ for lateral sides, and $(1,2)$ for the central location, respectively.
The critical perforation velocity of the bullet was found to be $70 \mathrm{~ms}^{-1}$ experimentally in which the bullet got trapped/ suspended on the Al6061 alloy flat plate, which is shown in Figure 30.

4.3. Comparison of Bullet Impact Experiment and Numerical Simulation Results. In this section, numerical simulations were compared with experimental results at three different velocities such as $60 \mathrm{~ms}^{-1}, 65 \mathrm{~ms}^{-1}$, and $70 \mathrm{~ms}^{-1}$, respectively, as depicted in Figure 31. The experimental results and numerical simulation results show very good agreement with each other. The velocity of $70 \mathrm{~ms}^{-1}$ was found to be the critical perforation velocity and was validated with iSIGHT experimental tests. 

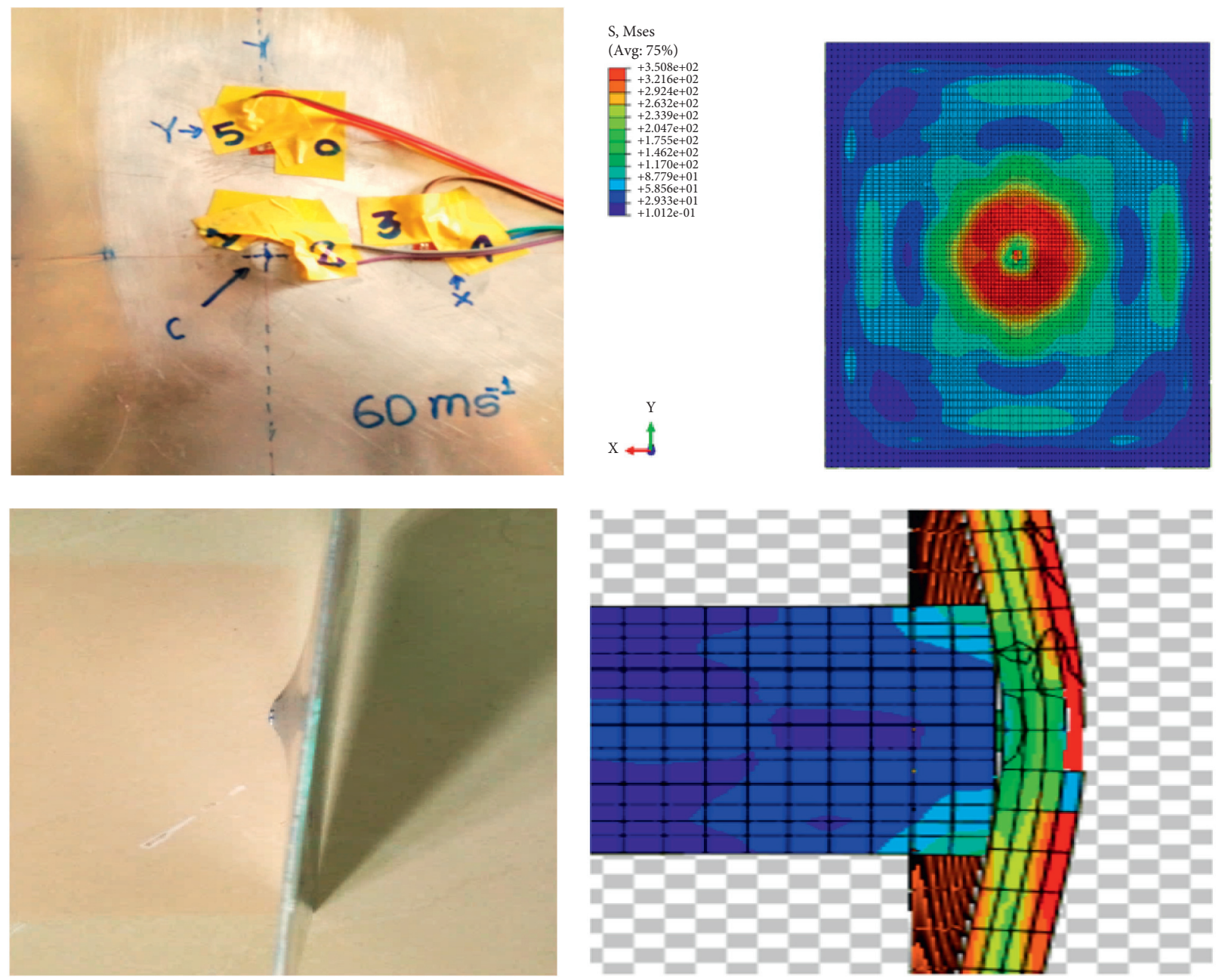

(a)

Figure 31: Continued. 

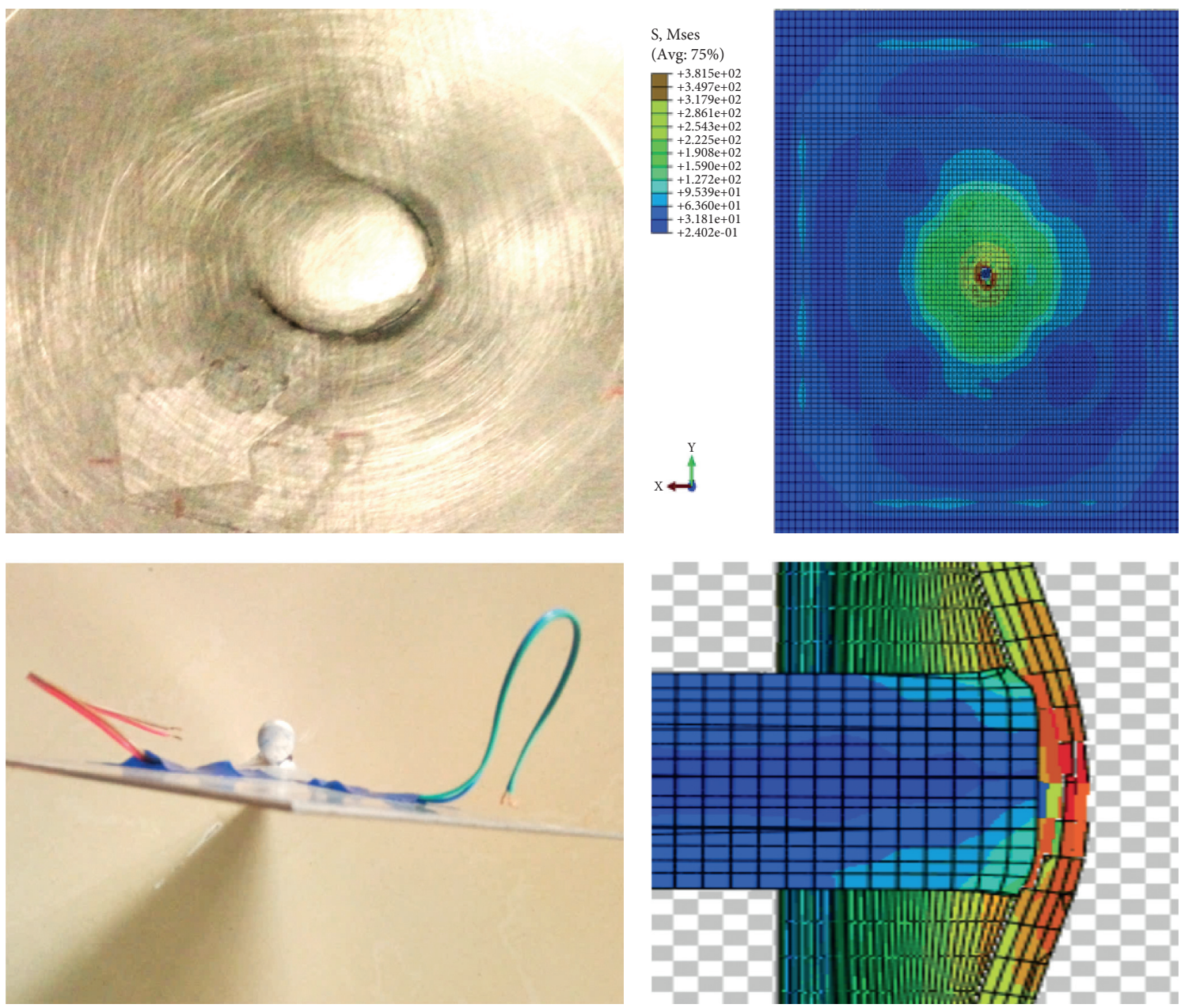

(b)

Figure 31: Continued. 

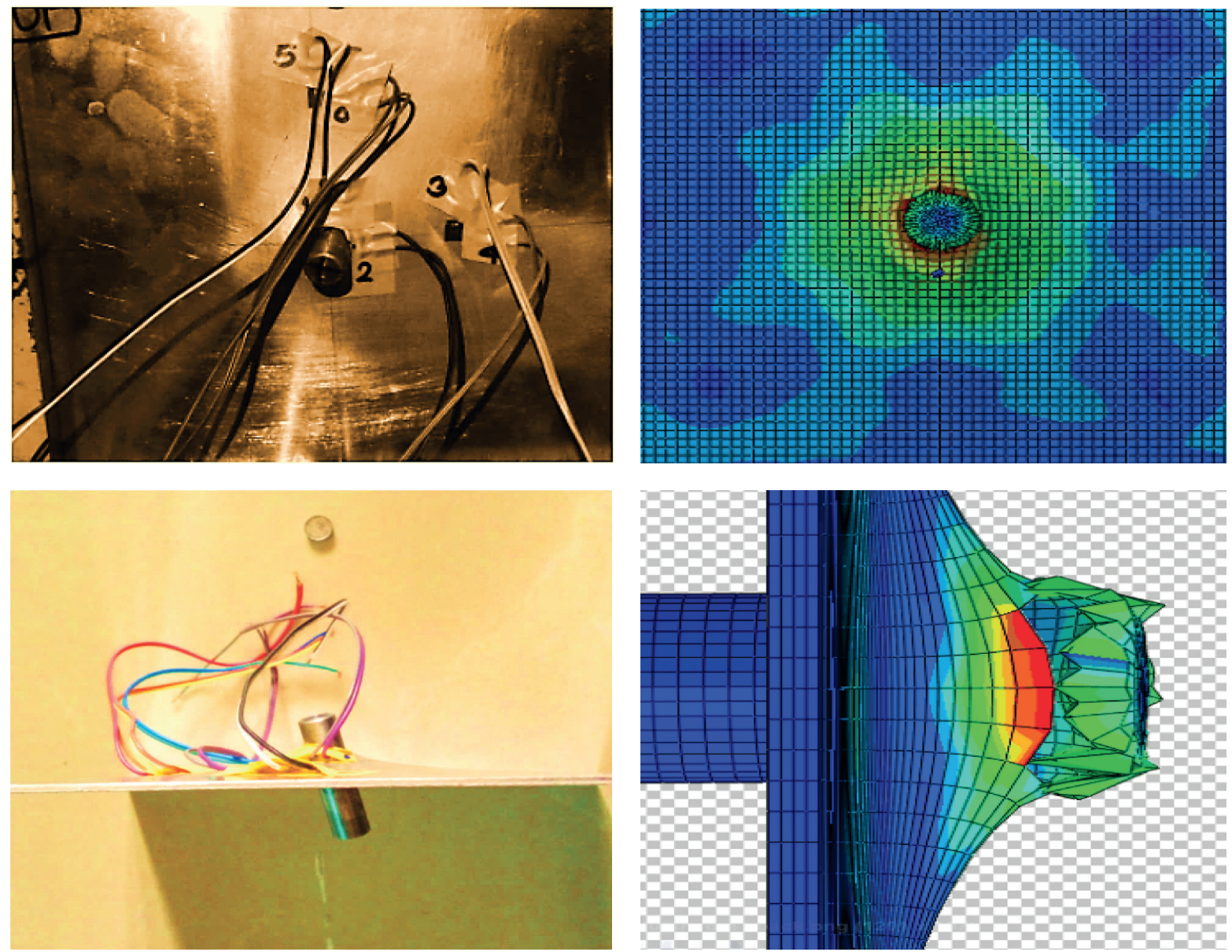

(c)

FIGURE 31: iSIGHT comparison of experimental results with numerical simulation results.

\section{Conclusions and Future Works}

The study was focused to validate critical perforation velocity numerically and experimentally. The following are the significant findings of the present study:

(1) The experimental results conclude that when the temperature and strain-rates increases, the yield and flow stress of Al6061 alloy also increase.

(2) The Johnson-Cook strength and fracture constants are evaluated of an Al6061 alloy utilizing Johnson-Cook constitutive model equation, which is obtained as follows: (i) strength constants such as $A, B, n, C$, and $m$ are $318.22599,395.36869,0.73707,0.01224$, and 1.77019 , respectively. (ii) fracture constants such as $D_{1}$, $D_{2}, D_{3}, D_{4}$, and $D_{5}$ are $0.08196,2.27659,-1.81322$, -0.07239 , and -0.00626 , respectively.

(3) Based on the experimental and numerical simulation results, the critical perforation velocity of stainless steel bullet impact is found to be $70 \mathrm{~ms}^{-1}$.

(4) The study results are expected to provide safety limits to the manufacturer assessing the impact-crashworthiness of $2 \mathrm{~mm}$ Al6061 alloy in aviation, marine, automobile, or defense fields.
(5) The Al6061 alloy may be accepted for future application where light-weight, moderate impact, good strength, and corrosion resistance are required.

Further study is needed to evaluate the Al6061 alloy responses when impacted with a certain angle and with a hemispherical nosed bullet.

\section{Appendix}

\section{A. Mechanical Behaviors under Quasi-Static Experimental Tests}

\section{B. Mechanical Behavior under Dynamic Experimental Tests}

\section{Calculation of Stress and Strain from the Experimental Tests}

Johnson-Cook failure constants

(1) Determination of $D_{1}, D_{2}$, and $D_{3}$

(i) Notched specimen 
(ii) Without notched specimen

(iii) Torsion

(2) Determination of $D_{4}$

(3) Determination of $D_{5}$

\section{Data Availability}

All data used to support the findings of this study are included within the article.

\section{Conflicts of Interest}

The authors declare that they have no conflicts of interest.

\section{Acknowledgments}

The authors would like to thank Northwestern Polytechnical University, the Department of Aeronautical Structure Engineering, and the Institute of Advanced Structures \& Materials (IASM) for providing experimental access facility to this research.

\section{References}

[1] L. Stemper, M. A. Tunes, R. Tosone, P. J. Uggowitzer, and S. Pogatscher, "On the potential of aluminum crossover alloys," Progress in Materials Science, vol. 124, Article ID 100873, 2021.

[2] E. M. Ruiz Navas and B. Ruiz Palenzuela, "Sintering of aluminum alloys. Processing and properties," in Encyclopedia of Materials: Metals and Allloys, F. G. Caballero, Ed., Elsevier, Oxford, UK, pp. 343-352, 2022.

[3] K. Singh, H. Singh, S. Vardhan, and S. Mohan, "An overview on the synthesis of aluminium matrix composites using stir casting technique," Materials Today Proceedings, 2021.

[4] V. Bhuvaneswari, L. Rajeshkumar, and K. Nimel Sworna Ross, "Influence of bioceramic reinforcement on tribological behaviour of aluminium alloy metal matrix composites: experimental study and analysis," Journal of Materials Research and Technology, vol. 15, pp. 2802-2819, 2021.

[5] J. Yin, Y. Cao, K. Wang, L. Lu, Y. Du, and Y. Yan, "Silver films on aluminum alloy 6061 modified by ion bombardment improves surface reflectivity," Vacuum, vol. 193, Article ID 110505, 2021.

[6] Y. Suo, Z. Deng, B. Wang, Y. Gong, and P. Jia, "Constitutive model of metal matrix composites at high strain rates and its application," Materials Today Communications, vol. 27, Article ID 102328, 2021.

[7] B. Jia, A. Rusinek, X. Xiao, and P. Wood, "Simple shear behavior of 2024-T351 aluminum alloy over a wide range of strain rates and temperatures: experiments and constitutive modeling," International Journal of Impact Engineering, vol. 156, Article ID 103972, 2021.

[8] Y. Song, J. Yeon, and G. Z. Voyiadjis, "Constitutive modeling and numerical simulations for dynamic strain aging in MMFX steel at elevated temperatures," International Journal of Mechanical Sciences, vol. 210, Article ID 106743, 2021.

[9] K. Yuan, W. Guo, P. Li, Y. Zhang, X. Li, and X. Lin, "Thermomechanical behavior of laser metal deposited Inconel 718 superalloy over a wide range of temperature and strain rate: testing and constitutive modeling," Mechanics of $\mathrm{Ma}$ terials, vol. 135, pp. 13-25, 2019.
[10] L. A. Peterson, M. F. Horstemeyer, T. E. Lacy, and R. D. Moser, "Experimental characterization and constitutive modeling of an aluminum 7085-T711 alloy under large deformations at varying strain rates, stress states, and temperatures," Mechanics of Materials, vol. 151, Article ID 103602, 2020.

[11] W. Zhou, J. Lin, D. S. Balint, and T. A. Dean, "Clarification of the effect of temperature and strain rate on workpiece deformation behaviour in metal forming processes," International Journal of Machine Tools and Manufacture, vol. 171, Article ID 103815, 2021.

[12] H. Chen, Z. Chen, J. Liu et al., "Constitutive modeling of flow stress and work hardening behavior while considering dynamic strain aging," Materialia, vol. 18, Article ID 101137, 2021.

[13] Z. Xu, Y. Liu, H. Hu, X. He, and F. Huang, "Thermo-viscoplastic behavior and constitutive modeling of pure copper under high-strain-rate shear condition," Mechanics of Materials, vol. 129, pp. 306-319, 2019.

[14] K. K. Rathore, Y. Jasra, and R. K. Saxena, "Numerical simulation of fracture behavior under high-velocity impact for aluminium alloy 6060 target plate," Materials Today Proceedings, vol. 28, pp. 1809-1815, 2020.

[15] R. Rai, G. Kumar, S. Dagar, V. Somashekar, C. A. Mboreha, and P. Modi, "Numerical simulation of ballistic impact on aluminium 5083-H116 plate with Johnson cook plasticity model," Materials Today Proceedings, vol. 46, Article ID 10619, 2021.

[16] K. Senthil and M. A. Iqbal, "Prediction of superior target layer configuration of armour steel, mild steel and aluminium 7075-T651 alloy against 7.62 AP projectile," Structures, vol. 29, pp. 2106-2119, 2021.

[17] T. Børvik, L. Olovsson, S. Dey, and M. Langseth, "Normal and oblique impact of small arms bullets on AA6082-T4 aluminium protective plates," International Journal of Impact Engineering, vol. 38, pp. 577-589, 2011.

[18] X. Xiao, Y. Shi, Y. Wang, X. Chen, and B. Jia, "Effect of incorporating Lode angle parameter into a fracture criterion in predicting ballistic impact behavior of double-layered 2024-T351 aluminum alloy plates against blunt projectiles," International Journal of Impact Engineering, vol. 160, Article ID 104082, 2022.

[19] D. Santha Rao and T. Shashank Simhadri, "Improvements in mechanical properties of aluminium alloy-titanium di boride and boron carbide hybrid composite produced through friction stir processing route," Materials Today Proceedings, vol. 45, pp. 5231-5236, 2021.

[20] A. Bala, S. Gupta, K. P. Paradeshi, and A. K. Dash, "Behavior of bamboo wall panel under bullet impact load," Materials Today Proceedings, vol. 32, pp. 904-909, 2020.

[21] G. Wu, X. Wang, C. Ji et al., "Anti-blast properties of 6063-T5 aluminum alloy circular tubes coated with polyurea elastomer: experiments and numerical simulations," Thin-Walled Structures, vol. 164, Article ID 107842, 2021.

[22] S. Bagwe, S. Thale, P. Sawant, and M. J. Pawar, "Finite element analysis of armor steel and aluminium alloy under the impact of $7.62 \mathrm{~mm}$ projectile," Materials Today Proceedings, vol. 44, pp. 4086-4091, 2021.

[23] B. Yuan, Z. Li, Z. Zhao, H. Ni, Z. Su, and Z. Li, "Experimental study of displacement field of layered soils surrounding laterally loaded pile based on transparent soil," Journal of Soils and Sediments, vol. 21, no. 9, pp. 3072-3083, 2021.

[24] B. Yang, D. Li, S. Yuan, and L. Jin, "Role of biochar from corn straw in influencing crack propagation and evaporation in sodic soils," Catena, vol. 204, Article ID 105457, 2021. 
[25] B. Yuan, Z. Li, Z. Su, Q. Luo, M. Chen, and Z. Zhao, "Sensitivity of multistage fill slope based on finite element model," Advances in Civil Engineering, vol. 2021, Article ID 6622936, 13 pages, 2021.

[26] K. Cui, X. Zhao, M. Hu, C. Yang, and G. Xie, "Effect of salt content on the evaporation and cracking of soil from heritage structures," Advances in Materials Science and Engineering, vol. 2021, Article ID 3213703, 9 pages, 2021.

[27] B. Yuan, Z. Li, Y. Chen et al., "Mechanical and microstructural properties of recycling granite residual soil reinforced with glass fiber and liquid-modified polyvinyl alcohol polymer," Chemosphere, vol. 286, Article ID 131652, 2022.

[28] B. Yang, K. Xu, and Z. Zhang, "Mitigating evaporation and desiccation cracks in soil with the sustainable material biochar," Soil Science Society of America Journal, vol. 84, no. 2, pp. 461-471, 2020.

[29] B. Bai, Q. Nie, Y. Zhang, X. Wang, and W. Hu, "Cotransport of heavy metals and $\mathrm{SiO} 2$ particles at different temperatures by seepage," Journal of Hydrology, vol. 597, Article ID 125771, 2021.

[30] B. Yang, S. Yuan, Y. Liang, and J. Liu, "Investigation of overburden failure characteristics due to combined mining: case study, Henan Province, China," Environmental Earth Sciences, vol. 80, no. 4, p. 143, 2021.

[31] B. Yang, J. Liu, X. Zhao, and S. Zheng, "Evaporation and cracked soda soil improved by fly ash from recycled materials," Land Degradation \& Development, vol. 32, no. 9, pp. 2823-2832, 2021.

[32] J. S. Kimm, J. A. Bergmann, F. Wöste, F. Pöhl, P. Wiederkehr, and W. Theisen, "Deformation behavior of 42CrMo4 over a wide range of temperatures and strain rates in Split-Hopkinson pressure bar tests," Materials Science and Engineering, vol. 826, Article ID 141953, 2021.

[33] M. K. Gupta, "Numerical simulation of AA7075 under high strain rate with different shape of striker of split Hopkinson Pressure bar," Materials Today Communications, vol. 26, Article ID 102178, 2021.

[34] M. A. Kariem, R. C. Santiago, R. Govender et al., "RoundRobin test of split Hopkinson pressure bar," International Journal of Impact Engineering, vol. 126, pp. 62-75, 2019.

[35] H. Nie, T. Suo, B. Wu, Y. Li, and H. Zhao, "A versatile split Hopkinson pressure bar using electromagnetic loading," International Journal of Impact Engineering, vol. 116, pp. 94-104, 2018.

[36] P. S. Follansbee, "Fundamentals of strength; principles, experiment, and applications of an internal state variable constitutive formulation," The Minerals, Metals \& Materials Society, John Wiley \& Sons, vol. 111, pp. 748-6011, , Hoboken, NJ, USA, 2013.

[37] L.-L. Wang, Foundation of Stress WavesElsevier The Boulevard, Amsterdam, The Netherlands, 2007.

[38] Y. Liu, M. Li, X.-w. Ren, Z.-b. Xiao, X.-y. Zhang, and Y.-c. Huang, "Flow stress prediction of Hastelloy C-276 alloy using modified Zerilli-Armstrong, Johnson-Cook and Arrhenius-type constitutive models," Transactions of Nonferrous Metals Society of China, vol. 30, no. 11, pp. 3031-3042, 2020.

[39] D. Remache, M. Semaan, J. M. Rossi, M. Pithioux, and J. L. Milan, "Application of the Johnson-Cook plasticity model in the finite element simulations of the nanoindentation of the cortical bone," Journal of the Mechanical Behavior of Biomedical Materials, vol. 101, Article ID 103426, 2020.

[40] Y. Guo, Y. Xie, D. Wang, L. Du, and J. Zhao, "An improved damage-coupled viscoplastic model for predicting ductile fracture in aluminum alloy at high temperatures," Journal of Materials Processing Technology, vol. 296, Article ID 117229, 2021.

[41] C. Sorini, A. Chattopadhyay, and R. K. Goldberg, "An improved plastically dilatant unified viscoplastic constitutive formulation for multiscale analysis of polymer matrix composites under high strain rate loading," Composites Part B: Engineering, vol. 184, Article ID 107669, 2020.

[42] A. Rudnytskyj, P. Simon, M. Jech, and C. Gachot, "Constitutive modelling of the 6061 aluminium alloy under hot rolling conditions and large strain ranges," Materials \& Design, vol. 190, Article ID 108568, 2020.

[43] F. L. Bresolin and J. M. Vassoler, "A numerical study of the constitutive characterization of thermoplastic materials submitted to finite strain," International Journal of Solids and Structures, vol. 206, pp. 456-471, 2020.

[44] G. R. Johnson and W. Cook, "A constitutive model and data for metals Subjected to large strains, high strain rates and high temperatures," in Proceedings of the 7th International Symposium on Ballistics, pp. 541-548, Hague, Netherlands, April 1983.

[45] B. Hopkinson, "A method of measuring the pressure produced in the detonation of high explosive or by the impact of bullets," Roy. Soc. Proc.vol. 74, p. 498, 1914.

[46] G. R. Johnson and W. H. Cook, "Fracture characteristics of three metals subjected to various strains, strain rates, temperatures and pressures," Engineering Fracture Mechanics, vol. 21, no. 1, pp. 31-48, 1985.

[47] D. Palumbo, R. De Finis, F. Ancona, and U. Galietti, "Damage monitoring in fracture mechanics by evaluation of the heat dissipated in the cyclic plastic zone ahead of the crack tip with thermal measurements," Engineering Fracture Mechanics, vol. 181, pp. 65-76, 2017.

[48] P. W. Bridgman, Studies in Large Plastic Flow and Fracture, McGraw-Hill, New York, NY, USA, 1952.

[49] J. R. Rice and D. M. Tracey, "On the ductile enlargement of voids in triaxial stress fields," Journal of the Mechanics and Physics of Solids, vol. 17, pp. 201-217, 1969.

[50] J. W. Hancock and A. C. Mackenzie, "On the mechanisms of ductile failure in high-strength steels subjected to multi-axial stress-states," Journal of the Mechanics and Physics of Solids, vol. 24, pp. 147-160, 1976.

[51] D. A. Prabowo, M. A. Kariem, and L. Gunawan, "The effect of specimen dimension on the results of the split-hopkinson tension bar testing," Procedia Engineering, vol. 173, pp. 608-614, 2017.

[52] G. C. Ganzenmüller, D. Plappert, A. Trippel, and S. Hiermaier, "A split-hopkinson tension bar study on the dynamic strength of basalt-fibre composites," Composites Part B: Engineering, vol. 171, pp. 310-319, 2019. 